
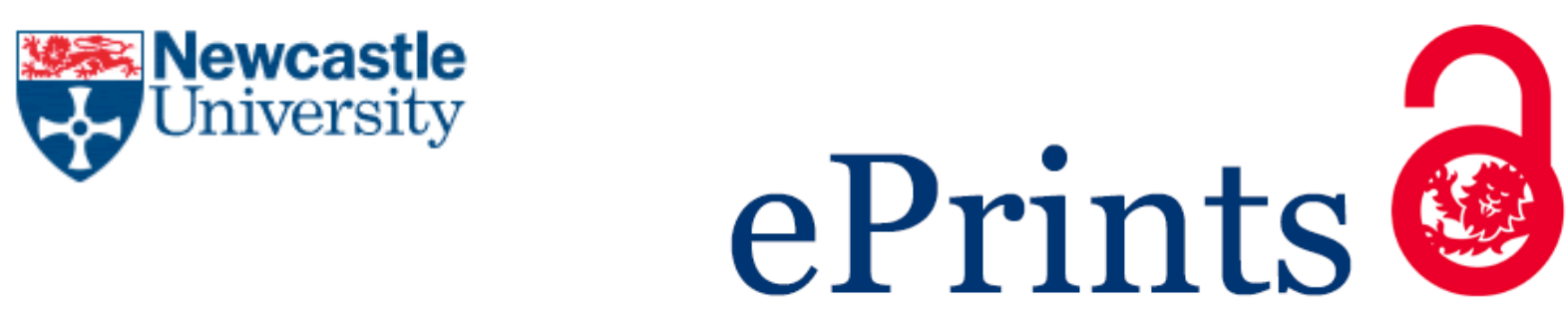

Powell J, Garnett J, Mather MW, Cooles FAH, Nelson A, Verdon B, Scott J, Jiwa K, Ruchaud-Sparagano MH, Cummings SP, Perry JD, Wright SE, Wilson JA, Pearson J, Ward C, Simpson AJ.

Excess Mucin Impairs Subglottic Epithelial Host Defense in Mechanically Ventilated Patients.

American Journal of Respiratory and Critical Care Medicine 2018 DOI: https://doi.org/10.1164/rccm.201709-18190C

Copyright:

Copyright ( 2017 by the American Thoracic Society. The final publication is available at https://doi.org/10.1164/rccm.201709-18190C

Date deposited:

$03 / 02 / 2018$ 


\section{Excess mucin impairs subglottic epithelial host defense in mechanically ventilated patients}

\begin{tabular}{|c|c|}
\hline Journal: & American Journal of Respiratory and Critical Care Medicine \\
\hline Manuscript ID & Blue-201709-18190C.R1 \\
\hline Manuscript Type: & OC - Original Contribution \\
\hline Date Submitted by the Author: & 05-Jan-2018 \\
\hline Complete List of Authors: & $\begin{array}{l}\text { Powell, Jason; Newcastle University Institute of Cellular Medicine, } \\
\text { Garnett, James; Newcastle University, Institute of Cellular Medicine } \\
\text { Mather, Michael; Newcastle University Institute of Cellular Medicine } \\
\text { Cooles, Faye; Newcastle University Institute of Cellular Medicine } \\
\text { Nelson, Andrew ; Northumbria university, Life Sciences } \\
\text { Verdon, Bernard; Newcastle University Medical School, Institutes of Cell \& } \\
\text { Molecular Biosciences } \\
\text { Scott, Jonathan; Newcastle University } \\
\text { Jiwa, Kasim; Newcastle university, Institute of Cellular medicine ; Freeman } \\
\text { Hospital, William Leech Centre for Lung Research } \\
\text { Ruchaud-Sparagano, Marie-Helene; Newcastle University } \\
\text { Cummings, Stephen; Northumbria university, Life Sciences } \\
\text { Perry, John; Freeman Hospital, } \\
\text { Wright, Stephen; Newcastle Upon Tyne Hospitals NHS Foundation Trust } \\
\text { Wilson, Janet; Freeman Hospital } \\
\text { Pearson, Jeffrey; Newcastle University Medical School, Institutes of Cellular } \\
\text { Medicine and Cell \& Molecular Biosciences } \\
\text { Ward, Chris; Freeman Hospital, William Leech Centre for Lung Research } \\
\text { Simpson, A; Newcastle University, Institute of Cellular Medicine }\end{array}$ \\
\hline Subject Category: & $\begin{array}{l}\text { 4.08 Mechanical Ventilation: Physiology \& Pathophysiology < CRITICAL } \\
\text { CARE }\end{array}$ \\
\hline Keywords: & Critical care, mucoproteins, phagocytosis, ventilator-associated pneumonia \\
\hline \multicolumn{2}{|c|}{$\begin{array}{l}\text { Note: The following files were submitted by the author for peer review, but cannot be converted to } \\
\text { PDF. You must view these files (e.g. movies) online. }\end{array}$} \\
\hline $\begin{array}{l}\text { Control mucin neuts.avi } \\
20 \mathrm{mg} \text { mucin neuts.avi }\end{array}$ & \\
\hline
\end{tabular}


Page 1 of 70 


\section{TITLE PAGE}

Full title: Excess mucin impairs subglottic epithelial host defense in mechanically ventilated patients

Authors: Jason Powell ${ }^{1}$, James Garnett ${ }^{1}$, Michael W Mather ${ }^{1}$, Faye A H Cooles ${ }^{1}$, Andrew Nelson $^{2}$, Bernard Verdon ${ }^{3}$, Jon Scott ${ }^{1}$, Kasim Jiwa ${ }^{1}$, Marie-Hélène Ruchaud-Sparagano ${ }^{1}$, Stephen P Cummings ${ }^{4}$, John D Perry ${ }^{5}$, Stephen E Wright ${ }^{6}$, Janet A Wilson ${ }^{7,8}$, Jeffrey Pearson $^{2}$, Chris Ward ${ }^{1 *}$, A John Simpson ${ }^{1 *} *$ equal contribution made

Affiliations: 1 - Institute of Cellular Medicine, Newcastle University, Newcastle upon Tyne, NE2 4HH, UK. 2 - Institute for Cell and Molecular Biosciences, Newcastle University, Newcastle upon Tyne, NE2 4HH, UK. 3 - Faculty of Health and Life Sciences, Northumbria University, Newcastle upon Tyne, NE1 8ST, UK. 4 - School of Science, Engineering and Design, Teesside University, Middlesbrough TS1 3BA, UK. 5 - Department of Microbiology, Freeman Hospital, Newcastle upon Tyne Hospitals NHS Foundation Trust, Newcastle upon Tyne, NE7 7DN, UK. 6 - Intensive Care Unit, Freeman Hospital, Newcastle upon Tyne Hospitals NHS Foundation Trust, Newcastle upon Tyne, NE7 7DN, UK. 7 - Institute of Health and Society, Newcastle University, Newcastle upon Tyne, NE2 4AX, UK. 8 Department of Otolaryngology - Head and Neck Surgery, Newcastle upon Tyne Hospitals NHS Foundation Trust, Newcastle upon Tyne, NE7 7DN, UK.

Corresponding authors: A John Simpson, Institute of Cellular Medicine, Newcastle University, Framlington Place, Newcastle upon Tyne, NE2 4HH, UK. tel: +44 (0)191 2087770, fax: +44 (0)191 2085066, email: j.simpson@ncl.ac.uk 
Author contributions: JaP, JoP, SEW, JAW, JeP, CW and AJS designed the study. JaP, JG, MWM, FAHC, AN, BV, JS, KJ, MHRS and SPC performed experiments. JaP, CW and AJS wrote the manuscript. All authors reviewed and approved the manuscript.

Financial support: Wellcome Trust grant 108768; Royal College of Surgeons of England Shears Grant; Royal Society of Medicine grant; Newcastle upon Tyne Hospitals NHS Charity; Newcastle University Wellcome Trust Institutional Strategic Support Fund; UK Medical Research Foundation Grant MRF-091-0001; and the Scottish Infection Research Network.

Running title: Subglottic host defense in mechanical ventilation Manuscript subject: 4.8 Mechanical Ventilation: Physiology \& Pathophysiology Manuscript word count: 3456 words

Research impact: Detailed characterization of the infective subglottic secretions that cause ventilator-associated pneumonia (VAP) in mechanically ventilated patients has not been performed before, and should suggest targeted interventions for the prevention of VAP. This study shows that intubation and mechanical ventilation in critically ill patients creates an inflammatory subglottic environment in which mucin hyper-secretion and enhanced viscosity is associated with neutrophil infiltration, impaired neutrophil function, release of neutrophil elastase, and enrichment of VAP-causing pathogens. Enhanced subglottic mucus removal and/or disruption appears to be a logical target for improved VAP prevention, and should be the focus of future trials. 


\section{At a Glance Summary:}

\section{Scientific Knowledge on the Subject}

"Blind" subglottic secretion drainage (SSD) significantly reduces VAP in mechanically ventilated patients. However remarkably little is known about the subglottic microenvironment in critically ill patients, and an improved understanding seems likely to suggest ways of improving the efficacy of SSD.

\section{What the Study Adds to the Field}

The study shows for the first time that, in critically ill patients, prolonged mechanical ventilation is associated with mucin hyper-secretion, mucus hyper-viscosity, neutrophilic inflammation, reduced microbiological diversity and enrichment of known respiratory pathogenic bacteria in subglottic secretions. Neutrophil proteases are secreted into the subglottic environment. We demonstrate that mucin from the subglottis of mechanically ventilated patients impairs the capacity of neutrophils to migrate, and to phagocytose and kill bacteria, and that the dysfunction is reversed upon treatment with a mucolytic agent. The study also adds a novel air-liquid interface model using primary human subglottic epithelium, in which subglottic mucin promotes growth and invasion of bacterial pathogens. These data begin to explain the association between subglottic host defense dysregulation, microbiological changes and VAP, and importantly suggest novel preventive strategies.

Online data supplement: This article has an online data supplement, which is accessible from this issue's table of content online at www.atsjournals.org 


\begin{abstract}
Rationale: Aspiration of infective subglottic secretions causes ventilator-associated pneumonia (VAP) in mechanically ventilated patients. Mechanisms underlying subglottic colonization in critical illness have not been defined, limiting strategies for targeted prevention of VAP.
\end{abstract}

Objectives: To characterize subglottic host defense dysfunction in mechanically ventilated patients in the intensive care unit (ICU). To determine whether subglottic mucin contributes to neutrophil phagocytic impairment and bacterial growth.

Methods: Prospective subglottic sampling in mechanically ventilated patients (intubated for four or more days), and newly intubated control patients (intubated for less than 30 minutes). Isolation and culture of primary subglottic epithelial cells from controls. Laboratory analysis of host innate immune defenses.

Measurements and Main Results: Twenty-four patients in the ICU and 27 newly intubated control patients were studied. Subglottic ICU samples had significantly reduced microbiological diversity and contained potential respiratory pathogens. The subglottic microenvironment in ICU was characterized by neutrophilic inflammation, significantly increased pro-inflammatory cytokines and neutrophil proteases, and altered physical properties of subglottic secretions, including accumulation of mucins. Subglottic mucin from ICU patients impaired the capacity of neutrophils to phagocytose and kill bacteria. Phagocytic function was reversible upon treatment with a mucolytic agent. Subglottic mucus 
promoted growth and invasion of bacterial pathogens in a novel air-liquid interface model of primary human subglottic epithelium.

Conclusions: Mechanical ventilation in ICU is characterized by substantial mucin secretion and neutrophilic inflammation. Mucin impairs neutrophil function and promotes bacterial growth. Mucolytic agents reverse mucin-mediated neutrophil dysfunction. Enhanced mucus disruption and removal has potential to augment preventive benefits of subglottic drainage.

Word count: 249 words

Key words: Critical care, mucoproteins, neutrophils, phagocytosis, ventilator-associated pneumonia. 


\section{TEXT}

\section{INTRODUCTION}

Ventilator-associated pneumonia (VAP) is a common complication in the intensive care unit (ICU), with 9 - 27\% of intubated and mechanically ventilated patients developing the condition (1-3). VAP remains the most commonly fatal infection in critical illness, with an overall attributable mortality of $13 \%$ (4). VAP significantly increases the length and cost of ICU stay (5), accounts for half of all antibiotics given in critical care (6), and is commonly associated with antibiotic-resistant pathogens (7-9).

Introduction of the endotracheal tube (ETT) is a key contributing factor in VAP, providing a conduit for invasion of the airways with virulent microorganisms $(10,11)$. Bacteria cultured from the upper airway, above the ETT cuff prior to development of VAP, correlate strongly with organisms subsequently isolated from the lungs (12-14). Micro-aspiration of infected secretions from the subglottis (the region located immediately below the vocal cords, and directly above the ETT cuff) into the lung is considered a key component in the pathogenesis of VAP. Indeed, subglottic secretion drainage (SSD) has consistently emerged as an effective strategy for prevention of VAP (15-20), resulting in SDD being recommended in key guidelines and position statements (21-25). Despite this, little is known about the subglottic microenvironment in critically ill patients. Identification of factors associated with bacterial colonization of the subglottis would likely suggest novel, logical targets for improved prevention of VAP.

The aims of this study were therefore to characterize subglottic host defenses in critically ill patients intubated in ICU, through a systematic evaluation of subglottic microbes, 
neutrophils, mucus and epithelium. Our data propose a significant role for mucins in neutrophil dysfunction and propagation of bacterial growth. Some of the results of these studies have been previously reported in the form of an abstract (26).

\section{METHODS}

\section{Patients and volunteers}

Patients who were intubated and mechanically ventilated for $\geq 4$ days were recruited from two ICUs. Controls had elective laryngoscopy under general anesthesia for a range of upper airway symptoms of unidentified cause. Both groups had subglottic secretions aspirated under direct endoscopic vision. Controls also had subglottic brushings collected for epithelial culture using a sheathed cytology brush (BC-202D-5010, Olympus, Tokyo, Japan). Healthy volunteers provided blood to generate neutrophils for in vitro experiments. Further details relating to subglottic sampling and blood sampling are in the online supplement. Informed, witnessed assent (from a relative or main carer for patients in the ICU) or informed, written consent (from controls and healthy volunteers) was obtained. The relevant research ethics committees approved the study.

\section{Processing of subglottic aspirates and blood}

Leukocytes were isolated from freshly aspirated mucus samples treated with $0.08 \%$ dithiothreitol (DTT, a mucolytic agent) (27) and from whole blood (28). Isolated cells were counted using a hemacytometer. Cytospins were prepared and cells stained with Giemsa to allow identification at light microscopy. Details of processing are in the online supplement. 


\section{Bacterial and fungal identification in subglottic aspirates}

Semi-quantitative bacterial and fungal culture, in addition to $16 \mathrm{~S}$ rRNA bacterial profiling was performed on subglottic aspirates (details are contained in the online supplement) (29).

Quantification of inflammatory cytokines, complement factors, mucins, DNA and proteases

Cytokines were assayed by V-PLEX and U-PLEX kits (Meso Scale Diagnostics, MD, USA). Human neutrophil elastase (HNE) was quantified by enzyme-linked immunosorbent assay (ELISA, Abcam, MA, USA). Cytometric bead array (Becton Dickinson Biosciences, NJ, USA) was used to quantify C5a des-Arg (a stable form of activated complement factor 5). A Quanti-iT flourometric assay kit (Thermofisher, MA, USA) was used to quantify doublestranded DNA (dsDNA). Further details are provided in the online supplement.

\section{Neutrophil viability}

Proportions of viable, apoptotic or necrotic cells were estimated using flow cytometry. Neutrophils were stained with Annexin V (Ann V, which binds to phosphatidylserine on the outer surface of apoptotic cells) and propidium iodide (PI, a vital dye that only enters and stains cells with a compromised cell wall, such as necrotic or late apoptotic cells). Samples were analyzed immediately using a FACSCanto II flow cytometer (Becton Dickinson Biosciences, NJ, USA) and the percentage of cells defined as AnnV-/PI-, AnnV+/PI- or PI+, corresponding to live, early apoptotic or late apoptotic/necrotic cells respectively (see online supplement for greater detail and representative flow cytometry plots) (30).

\section{Phagocytosis and bacterial killing by neutrophils}


Phagocytosis by mucus- or blood-derived neutrophils was estimated using flow cytometric quantification of pHrodo ${ }^{\circledR}$ Green Staphylococcus aureus Bioparticles ${ }^{\circledR}$ (Thermofisher, MA, USA) taken up by neutrophils (see online supplement for greater detail and representative flow cytometry plots) (31). Neutrophils were also incubated with live Pseudomonas aeruginosa and bacterial killing estimated as a percentage of $P$. aeruginosa colony forming units (CFU), determined by serial dilution and incubation on Lennox B agar plates, compared to a no neutrophil control (see online supplement) (32).

\section{Neutrophil chemotaxis assay}

Chemotaxis was determined as the proportion of neutrophils migrating into the lower chamber of a transwell permeability support $(3.0 \mu \mathrm{m}$ pore size, Corning, NY, USA) containing recombinant human interleukin (IL)-8 (Sigma-Aldrich, Dorset, UK; see online supplement) (33).

\section{Mucus analysis and mucin purification}

Shear viscosity of mucus was analyzed at $37^{\circ} \mathrm{C}$ using a Kinexus Pro (Malvern Instruments, Worcester, UK) with $60 \mathrm{~mm}$ parallel plates, according to the manufacturer's instructions. A table of shear rates was produced over the range of $0-100 \mathrm{~s}^{-1}$. Analysis was performed on rSpace software (version 1.6, Malvern Instruments, Worcester, UK) (34). The percentage dry weight of mucus was calculated using a microbalance to compare weight before and after drying the sample at $80^{\circ} \mathrm{C}$ overnight. The principal mucins in mucus are MUC5B and MUC5AC and these were quantified by ELISA (Abcam, MA, USA).

Mucin was purified from subglottic aspirates as a single species by cesium chloride equilibrium density gradient ultracentrifugation and dialysis (see online supplement) (35). 
The mucin applied to cells in experiments therefore contained "total mucin", containing representative proportions of all constituent mucins. Total mucin (across a range of concentrations) was incubated with neutrophils (and the phagocytosis/bacterial killing assays repeated) and with epithelial cells (as described below).

\section{Primary subglottic epithelial cell (PSEC) culture}

Subglottic brushings were collected from newly intubated theater attender controls as described above. Epithelial cells were isolated and grown at air-liquid interface (ALI) (see online supplement) (36). Cultures were assessed (a) by light microscopy for the presence of apical cilia and (b) using an epithelial volt-ohmmeter (World Precision Instruments, FL, USA) to assess trans-epithelial electrical resistance. Separately, cells were stained with anticytokeratin antibody conjugated with Alexa Fluor ${ }^{\circledR} 647$ (Biolegend, CA, USA), counterstained with DAPI nuclear stain, and assessed by confocal microscopy (details are described in the online supplement).

\section{Bacterial-epithelial co-culture experiments}

PSECs, cultured at ALI, had their apical mucus layer replaced with purified mucin and were co-cultured with $P$. aeruginosa. At 7 hours the mucin layer was removed and the epithelial layer homogenized. Bacterial growth was determined by serial dilution and incubation on LB agar plates (see online supplement) (37).

\section{Statistical Analysis}

Analysis was conducted with Prism (Graphpad Software, CA, USA). Nonparametric data were analyzed by the Mann-Whitney $U$ test for two variables and by the Kruskal-Wallis test for greater than two variables, using Dunn's post-hoc analysis test. Categorical data were 
assessed by Fisher's exact test. Correlations were assessed by linear regression. $P<0.05$ was considered statistically significant.

\section{RESULTS}

\section{Patients and controls}

We enrolled 24 patients intubated and mechanically ventilated for $\geq 4$ days and 31 newly (and transiently) intubated non-ICU controls. Of these, all the ICU patients and 27 controls had recoverable subglottic secretions and were included in the study. Clinical and demographic information for both cohorts are described in Table 1. Extended clinical details for the ICU cohort are described in the online supplement (Table E1). No oral antiseptics or ETTs coated with antimicrobial agents were used in our patients. Two of the 24 ICU patients had a clinical diagnosis of VAP made at the time of study or in the following 4 days.

\section{Microbiological analysis}

The range of organisms identified in the subglottic aspirates of intubated and ventilated ICU patients was significantly lower than that of newly intubated controls (Figure 1). More species recognized as potential respiratory pathogens complicating critical illness (e.g. Pseudomonas, Enterococcus) were isolated from patients in the ICU (Figure 1 and online supplement Figure E1). Control samples tended to contain more commensal species, each in larger numbers, than ICU patients' samples (Figure 1, Figure E1, Table E2). 


\section{Analysis of mucins}

To establish the constituents and physical properties of subglottic mucus aspirates we assessed viscosity and percentage dry weight (percentage of solids), and quantified double stranded DNA (dsDNA) and the concentrations of the principal airway mucins MUC5B and MUC5AC (Figure 2). Mucus derived from patients in the ICU was significantly more viscous, and had a greater dry weight. In addition, significantly higher concentrations of dsDNA and mucin MUC5B (but not MUC5AC) were demonstrated, as compared to mucus from newly intubated controls. MUC5B was by far the most abundant mucin in mucus from ICU patients.

To investigate potential correlates between mucin concentrations in the subglottic aspirates and clinical status, total mucin concentrations in ICU subglottic aspirates were compared with various parameters. Subglottic mucin concentrations showed a weak, positive (but statistically significant) correlation with duration of intubation/mechanical ventilation and increasing age ( $\mathrm{r}=0.48, \mathrm{p}<0.05$ for both; see online supplement Figure E2).

\section{Analysis of markers of inflammation}

Significantly higher concentrations of inflammatory cytokines, activated complement, and extracellular HNE were observed in subglottic aspirates from the ICU patients (Table 2).

Neutrophil concentrations were also significantly elevated in the subglottic aspirates taken from patients in the ICU compared to controls (Figure 3). There was no significant difference in macrophage concentration (Figure 3). No significant difference was demonstrable between the portion of viable or apoptotic neutrophils in the two cohorts (Figure 3). A representative flow cytometry plot is shown in the online supplement, along with evidence that mucin itself 
did not compromise neutrophil viability (Figure E3). Given the large number of mucusderived neutrophils we went on to investigate the phagocytic capacity of these cells upon extraction from mucus samples. There was no demonstrable deficiency in phagocytic capacity of neutrophils extracted from the subglottic mucus of long-term intubated ICU patients, compared to newly intubated controls (Figure 3).

\section{Mucin-neutrophil interactions}

To assess whether the high mucin environment in the subglottis was responsible for neutrophil dysfunction, we incubated blood-derived neutrophils from healthy volunteers (who were not intubated at any point) with purified mucin, derived from subglottic secretions taken from patients in ICU. Mucin (at a concentration of $20 \mathrm{mg} / \mathrm{mL}$ ) induced a significant reduction in neutrophil chemotaxis compared to a mucin-free control (Figure 4A). This mucin concentration was selected as it approximated to the median concentration of mucin in ICU patients, and was more than twice the highest mucin concentration observed in any control. Neutrophil migration appeared to be paralyzed by high concentrations of mucin (see online supplement video, Figure E4). Additionally, mucin $(20 \mathrm{mg} / \mathrm{mL})$ significantly impaired the capacity of neutrophils to kill $P$. aeruginosa, one of the two most commonly isolated pathogens in VAP (Figure 4B) $(1,9)$. There was no significant reduction in either neutrophil chemotaxis or bacterial killing at the range of mucin concentrations found in subglottic aspirates from newly intubated controls. To corroborate these findings a further assay of phagocytosis by neutrophils from healthy volunteers was performed using $S$. aureus bioparticles $(S$. aureus is the other of the two commonest pathogens causing $\operatorname{VAP}(1,9))$. Mucin at $20 \mathrm{mg} / \mathrm{mL}$ again impaired phagocytosis (Figure 4C). DTT (a mucolytic agent) reversed the mucin-associated impairment of phagocytosis (Figure 4C). 


\section{Effects of mucus on bacterial interaction with subglottic epithelium}

To investigate potential interactions between infected mucus and the subglottic epithelium, we developed a novel in vitro ALI model of human PSECs and extensively characterized the model to determine how closely it recapitulated the in vivo environment (further detail and illustration is provided in the online supplement, Figures E5-7). An epithelial phenotype was confirmed by expression of pan-cytokeratin and at ALI the cells demonstrated a highly differentiated pseudostratified respiratory epithelium with apical cilia (Figure E5). Transepithelial electrical resistance was demonstrated at ALI and maintained in prolonged culture (Figures E5 and E6). Cultures also secreted appropriate airway mucins into an apical mucus layer (Figure E7).

The human PSEC model was used to investigate the interaction of the epithelium, $P$. aeruginosa, and purified mucin derived from patients in the ICU. Replacement of the PSECs' apical mucus layer with purified ICU-derived mucin (at a concentration of $20 \mathrm{mg} / \mathrm{mL}$ ), induced a significant increase in bacterial colony forming units (CFU), compared to a mucinfree control (Figure 5). This was evident in both the apical mucin layer, and in the epithelial homogenate.

\section{DISCUSSION}

Our data suggest, for the first time, that intubation and mechanical ventilation in the ICU over 4 or more days is associated with neutrophilic inflammation and reduced microbiological 
diversity within the subglottic environment. Neutrophil function appears to be significantly impaired, at least in part due to an excess of subglottic mucin, which promotes colonization and growth of potential respiratory pathogens, and potentially invasion of the subglottic epithelium. These findings may explain the validated importance of SSD in the prevention of VAP, and suggest further preventive strategies. We also describe a novel in vitro model that reproduces several key features of the human subglottis.

Aspiration of infective subglottic secretions into the lung causes VAP in mechanically ventilated patients. We found that the microbiology of subglottic aspirates from intubated, critically ill patients shows reduced diversity and the presence of more pathogenic organisms associated with VAP, compared with controls.

It has previously been reported that even short-term tracheal intubation, for several hours, can cause significant mucosal inflammation around the tracheal cuff (38), and impede the function of the mucociliary escalator (39). This inflammation was characterized by a rapid accumulation of granulocytes and increased pro-inflammatory and chemotactic agents, such as IL-8, IL-6, IL-1 $\beta$ and C5a (38). We also found elevated pro-inflammatory cytokines in subglottic aspirates from patients in the ICU, which may have contributed to the recruitment, and persistence, of unexpectedly high concentrations of viable neutrophils. The release of HNE, a serine protease with a broad range of substrates, is likely to have further precipitated the local inflammation, which may in turn contribute to a cycle of further neutrophil migration (40).

The persisting inflammation described above may have contributed to the differences in the mucus constituents and physical properties of ICU-derived mucus. In particular IL-8, IL-6 and IL-1 $\beta$ have been shown to up-regulate MUC5B (41-44), and in murine models of cystic 
fibrosis-like lung disease neutrophil elastase appears to drive mucus hyper-secretion (45). In human studies, the inflammatory stimulus of e-cigarettes simultaneously produces airway neutrophilia and mucus hyper-secretion (46).

Mucins are one of the main constituents of the mucus that covers epithelial surfaces, and are vital in determining mucus function as a lubricant and selective barrier. The predominant secreted airway mucins are MUC5B and MUC5AC (47). The proportion of these two airway mucins within the airway is not well characterized in man. Both are secreted by goblet cells and seromucinous glands of the lamina propria at the apical epithelium (47). Consistent with our data, MUC5B appears to be the airway mucin most responsive to stimulation by inflammatory mediators. In keeping with this, MUC5B is the predominant airway mucin in chronic obstructive pulmonary disease (48).

Acute mucin hyper-secretion is thought to aid innate immune defense by trapping particles (47). Nevertheless prolonged, extensive or inappropriate mucin hyper-secretion has been implicated in airway obstruction and poor clearance of pathogens in numerous respiratory diseases (47). Our observation of high concentrations of mucin and dsDNA, as well as elevated mucus viscosity, suggest a potential failure of the mucus layer as an effective lubricant in the subglottis of critically ill patients. In parallel with the failure of the mucociliary escalator, demonstrated previously after intubation (39), this is likely to promote mucus stasis and a failure to clear pathogens.

The neutrophil is the key innate immune cell involved in clearance of bacteria and fungi (49). Mucin's inhibitory effect on phagocytosis by neutrophils is the most profound for any studied by our group to date. We have previously studied the effects of several cytokines and 
mediators (most of those described in Table 2) on neutrophil phagocytosis and found that only supra-physiological concentrations of C5a drive down-regulation (32). In contrast, GMCSF and IFN-gamma improve neutrophil phagocytosis. We cannot exclude the possibility that $\mathrm{C} 5 \mathrm{a}$ contributed to impaired neutrophil phagocytosis in our patients but the concentrations described here are associated with a small impairment of neutrophil phagocytosis in in vitro experiments (in contrast to the profound effect of mucin). Based on the available evidence we believe the most likely sequence is that, in the context of critical illness: intubation markedly upregulates local inflammation and cytokine production; this simultaneously recruits an excess of neutrophils and drives mucus hyper-secretion; mucus (with a smaller potential contribution from $\mathrm{C} 5 \mathrm{a}$ ) profoundly impairs the ability of neutrophils to clear bacteria, while mucus itself provides a compatible environment for bacterial growth; dysfunctional neutrophils release HNE, which may contribute further to local inflammation, potentially creating a vicious cycle.

We observed no demonstrable difference in phagocytic function between subglottic mucusderived neutrophils from patients in ICU or controls (Figure 3C). It should be emphasized that neutrophil functions were not measured in mucus aspirated fresh from patients (as neutrophils are "trapped" in the mucus, and the number of neutrophils and other leukocytes cannot be standardized), and that Figure $3 \mathrm{C}$ shows neutrophils liberated from mucus by a mucolytic (and studied at a known concentration).

Blood neutrophil phagocytic capacity was also similar in ICU patients and controls. This was unsurprising, as in our experience very profound critical illness is required to impair blood neutrophil capacity (50) (our use of healthy volunteers' blood neutrophils in Figure 3C could be criticized but we were confident that control patients' blood neutrophil phagocytosis 
would be normal, and restricted their extra involvement to subglottic aspiration under direct vision).

We found that the phagocytic capacity of neutrophils in the subglottic aspirates from ICU patients and from controls was lower than that in blood neutrophils. This is consistent with our previous findings that extravascular neutrophils have lower phagocytic capacity than blood neutrophils from the same patient (32 and Hellyer TP, unpublished data). However, the phagocytic capacity of subglottic neutrophils from ICU patients remained equivalent to that from controls, and remained adequate for phagocytosis. While intubation and the inflammatory milieu may make a contribution to impaired neutrophil function, we believe these data suggest that neutrophils are functionally "trapped" by mucus. Importantly, however, they appear to retain function when removed from the mucus. We therefore went on to study the effect of purified mucin (from ICU patients) on healthy neutrophils. An in vitro cystic fibrosis model has suggested that high mucin concentrations may adversely affect neutrophils' capacity for chemotaxis and bacterial killing (33).

Purified mucin (predominantly containing MUC5B and MUC5AC) at a concentration and ratio typically found in intubated, critically ill patients impaired the capacity of healthy neutrophils to migrate towards a chemoattractant and to phagocytose and kill bacteria. Importantly, a mucolytic agent capable of breaking down mucin's polymeric structure, restored normal phagocytic function (Figure 4C) to levels observed in subglottic neutrophils from control patients (Figure 3C). This supports the earlier data suggesting that neutrophil function can be restored upon liberation from mucus. 
The novel human PSEC ALI model provides the potential to study subglottic diseases and potentially test therapeutic agents with a sub-site-specific in vitro model. The model provided evidence that subglottic mucin promotes growth and invasion of bacterial pathogens. This was a preliminary exploration of this concept and further validation is needed with other laboratory and clinical strains of VAP-producing pathogens, and the addition of neutrophils to the co-culture in the future.

We believe that the identification of excess subglottic mucus as (i) a substrate for bacterial propagation and (ii) a "disabling trap" for neutrophils, from which they can be functionally rescued, has some simple but potentially important clinical implications. In particular, more effective subglottic clearance by aspiration under direct vision and/or by physical or chemical disruption of subglottic mucus seems likely to decrease local infection and inflammation, while simultaneously creating an environment for more effective neutrophil function. Several of the ICU patients in this study were already having SSD, yet subglottic mucus was freely aspirated from all patients under direct vision, suggesting SSD is sub-optimally effective. We therefore believe the simple interventions of aspiration under direct vision and/or mucus disruption should be assessed in clinical trials with a view to establishing whether they can prevent VAP more effectively than SSD alone. Such studies will require careful design and substantial patient numbers in order to test whether VAP is effectively prevented.

In conclusion, intubated critically ill patients have an inflammatory subglottic phenotype characterized by mucin MUC5B hyper-secretion, emergence of potential respiratory pathogens, and release of neutrophil proteases such as HNE. The data suggest that more effective early removal and/or disruption of subglottic mucus represents an attractive strategy for improving prevention of VAP. 


\section{ACKNOWLEGMENTS}

The authors would like to thank: Carmen Scott, Verity Calder and Craig Samson in the Newcastle Critical Care Research Team for their help with recruitment, and Jane White in the surgical waiting list department for her help with recruitment. 


\section{REFERENCES}

1. Chastre J, Fagon JY. Ventilator-associated pneumonia. Am J Respir Crit Care Med 2002;165:867-903.

2. Urli T, Perone G, Acquarolo A, Zappa S, Antonini B, Ciani A. Surveillance of infections acquired in intensive care: usefulness in clinical practice. J Hosp Infect 2002;52:130135.

3. Rello J, Ollendorf DA, Oster G, Vera-Llonch M, Bellm L, Redman R, Kollef MH. Epidemiology and outcomes of ventilator-associated pneumonia in a large US database. Chest 2002;122:2115-2121.

4. Melsen WG, Rovers MM, Groenwold RH, Bergmans DC, Camus C, Bauer TT, Hanisch EW, Klarin B, Koeman M, Krueger WA, Lacherade JC, Lorente L, Memish ZA, Morrow LE, Nardi G, van Nieuwenhoven CA, O'Keefe GE, Nakos G, Scannapieco FA, Seguin P, Staudinger T, Topeli A, Ferrer M, Bonten MJ. Attributable mortality of ventilator-associated pneumonia: a meta-analysis of individual patient data from randomised prevention studies. Lancet Infect Dis 2013;13:665-671.

5. Kollef MH, Hamilton CW, Ernst FR. Economic impact of ventilator-associated pneumonia in a large matched cohort. Infect Control Hosp Epidemiol 2012;33:250-256.

6. Vincent JL, Bihari DJ, Suter PM, Bruining HA, White J, Nicolas-Chanoin MH, Wolff M, Spencer RC, Hemmer M. The prevalence of nosocomial infection in intensive care units in Europe. Results of the European Prevalence of Infection in Intensive Care (EPIC) Study. EPIC International Advisory Committee. JAMA1995;274:639-644.

7. Gupta R, Malik A, Rizvi M, Ahmed M, Singh A. Epidemiology of multidrug-resistant Gram-negative pathogens isolated from ventilator-associated pneumonia in ICU patients. J Global Antimicrob Resist 2017;9:47-50. 
8. Abd-Elmonsef MM, Elsharawy D, Abd-Elsalam AS. Mechanical ventilator as a major cause of infection and drug resistance in intensive care unit. Environ Sci Pollut Res Int 2017 Feb 23 [epub ahead of print].

9. Park DR. The microbiology of ventilator-associated pneumonia. Respir Care 2005;50:742763.

10. Pneumatikos IA, Dragoumanis CK, Bouros DE. Ventilator-associated pneumonia or endotracheal tube-associated pneumonia? An approach to the pathogenesis and preventive strategies emphasizing the importance of endotracheal tube. Anesthesiology 2009;110:673-680.

11. Zolfaghari PS, Wyncoll DL. The tracheal tube: gateway to ventilator-associated pneumonia. Crit Care 2011;15:310.

12. Berdal JE, Bjornholt J, Blomfeldt A, Smith-Erichsen N, Bukholm G. Patterns and dynamics of airway colonisation in mechanically-ventilated patients. Clin Microbiol Infect 2007;13:476-480.

13. Gil-Perotin S, Ramirez P, Marti V, Sahuquillo JM, Gonzalez E, Calleja I, Menendez R, Bonastre J. Implications of endotracheal tube biofilm in ventilator-associated pneumonia response: a state of concept. Crit Care 2012;16:R93.

14. Pirracchio R, Mateo J, Raskine L, Rigon MR, Lukaszewicz AC, Mebazaa A, Hammitouche Y, Sanson-Le Pors MJ, Payen D. Can bacteriological upper airway samples obtained at intensive care unit admission guide empiric antibiotherapy for ventilator-associated pneumonia? Crit Care Med 2009;37:2559-2563.

15. Dezfulian C, Shojana K, Collard HR, Kim HA, Matthay MA, Saint S. Subglottic secretion drainage for preventing ventilator-associated pneumonia. Am J Med 2005;118:11-18. 
16. Lacherade JC, De Jonghe B, Guezennec P, Debbat K, Hayon J, Monsel A, Fangio P, Appere de Vecchi C, Ramaut C, Outin H, Bastuji-Garin S. Intermitten subglottic secretion drainage and ventilator-associated pneumonia: a multicenter trial. Am J Respir Crit Care Med 2010;182:910-917.

17. Muscedere J, Rewa O, McKechnie K, Jiang X, Laporta D, Heyland DK. Subglottic secretion drainage for the prevention of ventilator-associated pneumonia: a systematic review and meta-analysis. Crit Care Med 2011;39:1985-1991.

18. Wang F, Bo L, Tang L, Lou J, Wu Y, Chen F, Li J, Deng X. Subglottic secretion drainage for preventing ventilator-associated pneumonia: an updated meta-analysis of randomized controlled trials. J Trauma Acute Care Surg 2012;72:1276-1285.

19. Damas P, Frippiat F, Ancion A, Canivet JL, Lambermont B, Layios N, Massion P, Morimont P, Nys M, Piret S, Lancellotti P, Wiesen P, D'orio V, Samalea N, Ledoux D. Prevention of ventilator-associated pneumonia and ventilator-associated conditions: a randomized controlled trial with subglottic secretion suctioning. Crit Care Med 2015;43:22-30.

20. Caroff DA, Li L, Muscedere J, Klompas M. Subglottic Secretion Drainage and Objective Outcomes: A Systematic Review and Meta-Analysis. Crit Care Med 2016;44:830840.

21. American Thoracic Society Infectious Diseases Society of America. Guidelines for the management of aduts with hospital-acquired, ventilator-associated, and healthcareassociated pneumonia. Am J Respir Crit Care Med 2005;171:388-416.

22. Masterton RG, Galloway A, French G, Street M, Armstrong J, Brown E, Cleverley J, Dilworth P, Fry C, Gascoigne AD, Knox A, Nathwani D, Spencer R, Wilcox M. Guidelines for the management of hospital-acquired pneumonia in the UK: Report of 
the Working Party on Hospital-Acquired Pneumonia of the British Society for Antimicrobial Chemotherapy. J Antimicrob Chemother 2008;62:5-34.

23. Rotstein C, Evans G, Born A, Grossman R, Light RB, Magder S, McTaggart B, Weiss K, Zhanel GG. Clinical practice guidelines for hospital-acquired pneumonia and ventilator-associated pneumonia in adults. Can $\mathrm{J}$ Infect Dis Med Microbiol 2008;19:19-53.

24. Torres A, Ewig S, Lode J, Carlet J; European HAP Working Group. Defining, treating and preventing hospital acquired pneumonia. Intensive Care Med 2009;35:9-29.

25. Hellyer TP, Ewan V, Wilson P, Simpson AJ. The Intensive Care Society recommended bundle of interventions for the prevention of ventilator-associated pneumonia. $\mathrm{J}$ Intensive Care Soc 2016;17:238-243.

26. Powell J, Garnett J, Verdon B, Wilson J, Pearson J, Ward C. A human in vitro model of the subglottic airway. Otolaryngol Head Neck Surg 2015;153:83.

27. Alexis N, Soukup J, Ghio A, Becker S. Sputum phagocytes from healthy individuals are functional and activated: a flow cytometric comparison with cells in bronchoalveolar lavage and peripheral blood. Clin Immunol 2000;97:21-32.

28. Scott J, Harris GJ, Pinder EM, Macfarlane JG, Hellyer TP, Rostron AJ, Conway Morris A, Thickett DR, Perkins GD, McAuley DF, Widdrington JD, Wiscombe S, Baudouin SV, Roy AI, Linnett VC, Wright SE, Ruchaud-Sparagano MH, Simpson AJ. Exchange protein directly activated by cyclic AMP (EPAC) activation reverses neutrophil dysfunction induced by beta2-agonists, corticosteroids, and critical illness. J Allergy Clin Immunol 2016;137:535-544.

29. Kozich JJ, Westcott SL, Baxter NT, Highlander SK, Schloss PD. Development of a dualindex sequencing strategy and curation pipeline for analyzing amplicon sequence data 
on the MiSeq Illumina sequencing platform. Appl Environ Microbiol 2013;79:51125120.

30. Salamone G, Giordano M, Trevani AS, Gamberale R, Vermeulen M, Schettinni J, Geffner JR. Promotion of neutrophil apoptosis by TNF-alpha. J Immunol 2001;166:3476-3483.

31. Rabinovitch PS, Robinson JP. Current protocols in cytometry. Hoboken: John Wiley and Sons, Inc; 2002.

32. Conway Morris A, Kefala K, Wilkinson TS, Dhaliwal K, Farrell L, Walsh T, Mackenzie SJ, Reid H, Davidson DJ, Haslett C, Rossi AG, Sallenave JM, Simpson AJ. C5a mediates peripheral blood neutrophil dysfunction in critically ill patients. Am J Respir Crit Care Med 2009;180:19-28.

33. Matsui H, Verghese MW, Kesimer M, Schwab UE, Randell SH, Sheehan JK, Grubb BR, Boucher RC. Reduced three-dimensional motility in dehydrated airway mucus prevents neutrophil capture and killing bacteria on airway epithelial surfaces. J Immunol 2005;175:1090-1099.

34. Wilcox MD, Van Rooij LK, Chater PI, Pereira de Sousa I, Pearson JP. The effect of nanoparticle permeation on the bulk rheological properties of mucus from the small intestine. Eur J Pharm Biopharm 2015;96:484-487.35. Taylor C, Allen A, Dettmar PW, Pearson JP. Two rheologically different gastric mucus secretions with different putative functions. Biochim Biophys Acta 2004;1674:131-138.

36. Forrest IA, Murphy DM, Ward C, Jones D, Johnson GE, Archer L, Gould FK, Cawston TE, Lordan JL, Corris PA. Primary airway epithelial cell culture from lung transplant recipients. Eur Respir J 2005;26:1080-1085. 
37. Patkee WR, Carr G, Baker EH, Baines DL, Garnett JP. Metformin prevents the effects of Pseudomonas aeruginosa on airway epithelial tight junctions and restricts hyperglycaemia-induced bacterial growth. J Cell Mol Med 2016;20:758-764.

38. Puyo CA, Dahms TE. Innate immunity mediating inflammation secondary to endotracheal intubation. Arch Otolaryngol Head Neck Surg 2012;138:854-858.

39. Li Bassi G, Zanella A, Cressoni M, Stylianou M, Kolobow T. Following tracheal intubation, mucus flow is reversed in the semirecumbent position: possible role in the pathogenesis of ventilator-associated pneumonia. Crit Care Med 2008;36:518-525.

40. Downey DG, Bell SC, Elborn JS. Neutrophils in cystic fibrosis. Thorax 2009;64:81-88.

41. Thai P, Loukoianov A, Wachi S, Wu R. Regulation of airway mucin gene expression. Annu Rev of Physiol 2008;70:405-429.

42. Bautista MV, Chen Y, Ivanova VS, Rahimi MK, Watson AM, Rose MC. IL-8 regulates mucin gene expression at the posttranscriptional level in lung epithelial cells. J Immunol 2009;183:2159-2166.

43. Chen Y, Thai P, Zhao YH, Ho YS, DeSouza MM, Wu R. Stimulation of airway mucin gene expression by interleukin (IL)-17 through IL-6 paracrine/autocrine loop. J Biol Chem 2003;278:17036-17043.

44. Fujisawa T, Chang MM, Velichko S, Thai P, Hung LY, Huang F, Phuong N, Chen Y, Wu R. NF-kappaB mediates IL-1beta- and IL-17A-induced MUC5B expression in airway epithelial cells. Am J Respir Cell Mol Biol 2011;45:246-252.

45. Gehrig S, Duerr J, Weitnauer M, Wagner CJ, Graeber SY, Schatterny J, Hirtz S, Belaaouaj A, Dalpke AH, Schultz C, Mall MA. Lack of neutrophil elastase reduces inflammation, mucus hypersecretion, and emphysema, but not mucus obstruction, in mice with cystic fibrosis-like lung disease. Am J Respir Crit Care Med 2014;189:1082-1092. 
46. Reidel B, Radicioni G, Clapp P, Ford AA, Abdelwahab S, Rebuli ME, Haridass P, Alexis NE, Jaspers I, Kesimer M. E-cigarette use causes a unique innate immune response in the lung involving increased neutrophilic activation and altered mucin secretion. Am J Respir Crit Care Med 2017 Oct 20 [epub ahead of print].

47. Rose MC, Voynow JA. Respiratory tract mucin genes and mucin glycoproteins in health and disease. Physiol Rev 2006;86:245-278.

48. Kirkham S, Kolsum U, Rousseau K, Singh D, Vestbo J, Thornton DJ. MUC5B is the major mucin in the gel phase of sputum in chronic obstructive pulmonary disease. Am J Respir Crit Care Med 2008;178:1033-1039.

49. Amulic B, Cazalet C, Hayes GL, Metzler KD, Zychlinsky A. Neutrophil function: from mechanisms to disease. Annu Rev Immunol 2012;30:459-489.

50. Conway Morris A, Brittan M, Wilkinson TS, McAuley DF, Antonelli J, McCulloch C, Barr LC, McDonald NA, Dhaliwal K, Jones RO, Mackellar A, Haslett C, Hay AW, Swann DG, Anderson N, Laurenson IF, Davidson DJ, Rossi AG, Walsh TS, Simpson AJ. C5a-mediated neutrophil dysfunction is RhoA-dependent and predicts infection in critically ill patients. Blood 2011;117:5178-5188. 
FIGURE LEGENDS

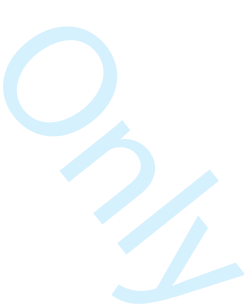




\section{Figure 1}

ICU subglottic aspirates are characterized by reduced microbiological diversity and the presence of more species recognized as potential respiratory pathogens than control secretions. (A) Semi-quantitative bacterial and fungal culture of subglottic aspirates. (B) $16 \mathrm{~S}$ rRNA bacterial profiling of subglottic aspirates. Observed operational taxonomic units (OTUs) and Shannon alpha diversity are demonstrated. The boxplots show the upper and lower quartiles and median, whiskers represent the range. (C) Hierarchical clustering of subglottic aspirate samples by bacterial relative abundance at OTU level. The row above the heat map shows ICU samples (orange) and control samples (blue) where each column represents a patient's sample. The 30 most abundant bacterial OTUs are displayed on the heat

map. A; Mann-Whitney U test, B; Kruskal-Wallis test, ${ }^{* *} \mathrm{p}<0.01, * * * \mathrm{p}<0.001$ (A; ICU n $=$ 23, control $\mathrm{n}=25$. B/C; ICU $\mathrm{n}=24$, control $\mathrm{n}=20$ ). 


\section{Figure 2}

ICU aspirates are more dehydrated and viscous, and contained a greater concentration of dsDNA and MUC5B, but not MUC5AC, than control mucus. (A) Mucus shear viscosity was analyzed at $37^{\circ} \mathrm{C}$. Values are expressed as pascal-seconds $(\mathrm{Pa} \cdot \mathrm{s})$ at a shear rate of $1 \mathrm{~s}^{-1}$. (B) Aspirates were weighed before and after dehydration overnight at $80^{\circ} \mathrm{C}$. The percentage solid was then calculated. $(C)$ dsDNA concentration was quantified by Quant-iT assay kit. (D) Mucin MUC5B and MUC5AC concentrations were quantified by ELISA. Each dot represents a sample from an individual patient. Long horizontal bars indicate medians, shorter horizontal bars indicate interquartile range. Statistical analysis was by Mann-Whitney U test, $* \mathrm{p}<0.05, * * \mathrm{p}<0.01, * * * * \mathrm{p}<0.0001$ 


\section{Figure 3}

ICU subglottic aspirates are dominated by high numbers of viable neutrophils, capable of phagocytosis. (A) Cells were extracted from subglottic aspirates by treatment with $0.08 \%$ DTT. Differential cell count was then performed using a hemacytometer and cytospin preparations. (B) Extracted cells were incubated with Annexin V and propidium iodide. Viable, early apoptotic and late apoptotic/necrotic cells were determined by flow cytometric gating of neutrophils. No significant difference between the two cohorts was demonstrated. (C) Cells were extracted from the whole blood of ICU patients or healthy volunteers (HV) using dextran sedimentation, or the mucus of ICU patients/control patients after treatment with $0.08 \%$ DTT. Extracted cells were incubated at $37^{\circ} \mathrm{C}$ for 1 hour with serum-opsonized pHrodo ${ }^{\circledR}$ green $S$. aureus Bioparticles. Phagocytosis was determined by flow cytometry. A negative control sample on ice was used in all experiments. Data in A and B are presented as box and whisker plots where the horizontal line depicts the median, boxes the interquartile range and whiskers the range. In $\mathrm{C}$, each dot represents a sample from an individual. Long horizontal bars indicate medians, shorter horizontal bars indicate interquartile range. Statistical analysis was by Kruskal-Wallis test and Dunn's post hoc test, ${ }^{*} \mathrm{p}<0.05$, $* * * * \mathrm{p}<0.0001(\mathrm{~A} ; \mathrm{ICU} \mathrm{n}=18$, control $\mathrm{n}=7 . \mathrm{B} ; \mathrm{ICU} \mathrm{n}=18$, control $\mathrm{n}=8$ ). 


\section{Figure 4}

Purified ICU-derived mucin inhibits neutrophil function and this effect is reversible with mucolytic treatment. (A) Neutrophil chemotaxis was measured using carboxyfluorescein succinimidyl ester (CFSE)-labeled neutrophils incubated within a transwell insert $(3.0 \mu \mathrm{m}$ pore size). The number of neutrophils that migrated from the apical compartment to the lower compartment (containing IL-8 at $10 \mathrm{ng} / \mathrm{mL}$ ) at 3 hours was established. (B) Bacterial killing was determined using P. aeruginosa PA01 (opsonized using serum from the same donor who provided neutrophils) incubated with neutrophils for 30 minutes. Serial dilution on agar plates was performed, and colonies counted at 24 hours to derive a percentage reduction in colony forming units (CFU), measured against a sample without neutrophils. (C) Neutrophil phagocytosis pre- and post-mucolytic treatment was measured. Cells were incubated in mucin for 30 minutes prior to treatment with $0.08 \%$ dithiothreitol (DTT) for 5 minutes, centrifuged and re-suspended in a solution without mucin. Untreated cells and DTT-treated cells were then incubated at $37^{\circ} \mathrm{C}$ for 1 hour with $\mathrm{pHrodo}{ }^{\circledR}$ green $S$. aureus Bioparticles ${ }^{\circledR}$ (opsonized using serum from the same donor who provided neutrophils). Phagocytosis was determined by flow cytometric gating of viable neutrophils with ingested particles versus a control sample on ice. Data are expressed as median and 95\% confidence interval. Kruskal-Wallis test and Dunn's post hoc test were used to compare the differences against the control without mucin. ${ }^{*} \mathrm{p}<0.05$. (A; $\left.\mathrm{n}=6, \mathrm{~B} ; \mathrm{n}=5 ; \mathrm{C} \mathrm{n}=6\right)$. 


\section{Figure 5}

Purified subglottic mucin from ICU patients increases bacterial growth and invasion in bacterial-epithelial co-culture experiments. The mucus layer of PSECs cultured at ALI was removed and replaced with $50 \mu \mathrm{L}$ of purified ICU-derived mucin $(0,5,10$ and $20 \mathrm{mg} / \mathrm{mL})$, and incubated for 1 hour $\left(37^{\circ} \mathrm{C} 5 \% \mathrm{CO}_{2}\right)$. P. aeruginosa $\left[5 \mu 1\left(2 \times 10^{7} \mathrm{CFU} / \mathrm{mL}\right)\right.$, strain PA01] was then applied apically and incubated for 7 hours. Bacterial growth in the mucin layer $(A)$ and epithelial homogenate $(B)$ was determined by serial dilution on agar plates, counting colony-forming units (CFU) at 24 hours. Data are expressed as median and 95\% CI. KruskalWallis test and Dunn's post hoc test were used to compare samples and the control without mucin, ${ }^{*} \mathrm{p}<0.05, \mathrm{n}=4$. 
TABLES

\begin{tabular}{|c|c|c|c|}
\hline & $\begin{array}{l}\text { ICU patients } \\
(n=24)\end{array}$ & $\begin{array}{l}\text { Newly intubated } \\
\text { controls }(n=27)\end{array}$ & $P$ Value \\
\hline Median age, years (range) & $66(20-79)$ & $58(35-79)$ & $0.43^{*}$ \\
\hline Percentage of patients male & 63 & 59 & $>0.99^{\dagger}$ \\
\hline $\begin{array}{l}\text { Median (IQR) time mechanically } \\
\text { ventilated }\end{array}$ & $5(4-6)$ days & $9(5-10)$ minutes & \\
\hline ICU mortality, $\%$ & 42 & NA & \\
\hline $\begin{array}{l}\text { Percentage receiving immunosuppressive } \\
\text { drugs (including corticosteroids) }\end{array}$ & 21 & 0 & \\
\hline $\begin{array}{l}\text { Percentage receiving systemic } \\
\text { antimicrobial drugs }\end{array}$ & 92 & 0 & \\
\hline
\end{tabular}

Table 1. Demographic and clinical data for patient and control groups.

Abbreviations: $\mathrm{ICU}=$ intensive care unit; $\mathrm{IQR}=$ interquartile range; $\mathrm{NA}=$ not applicable;

*B By Mann-Whitney U test

${ }^{\dagger}$ By Chi Squared test

At time of subglottic aspiration or during ICU admission prior to sampling 


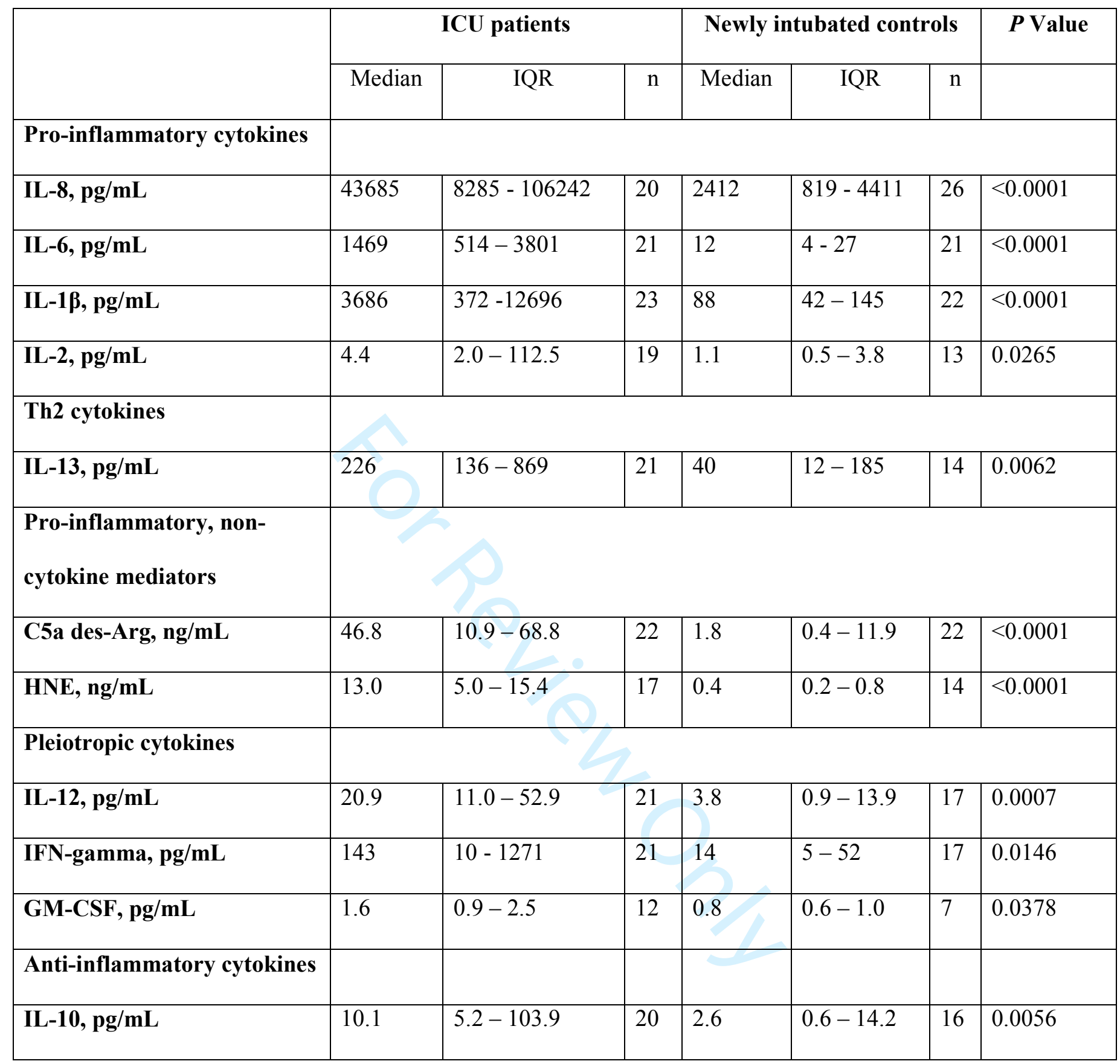

Table 2. Concentrations of cytokines and other mediators in subglottic aspirates.

Definition of abbreviations: C5a des-Arg, stable breakdown product of activated complement factor 5; GM-CSF, granulocyte-macrophage colony-stimulating factor; HNE, human neutrophil elastase; ICU = intensive care unit; IFN, interferon; IQR, interquartile range; Th, T helper cell. The Mann-Whitney U test was used for statistical comparisons. 

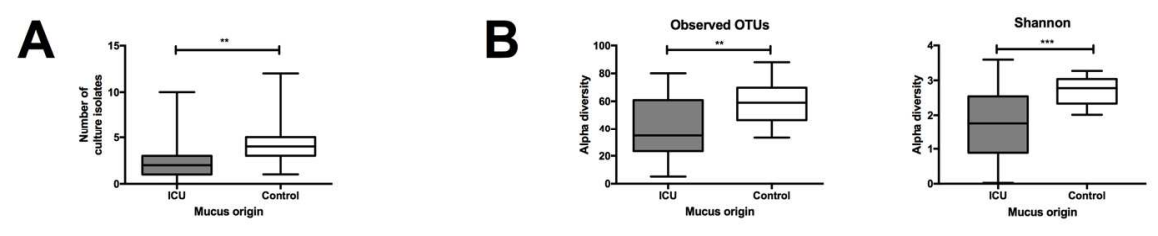

C

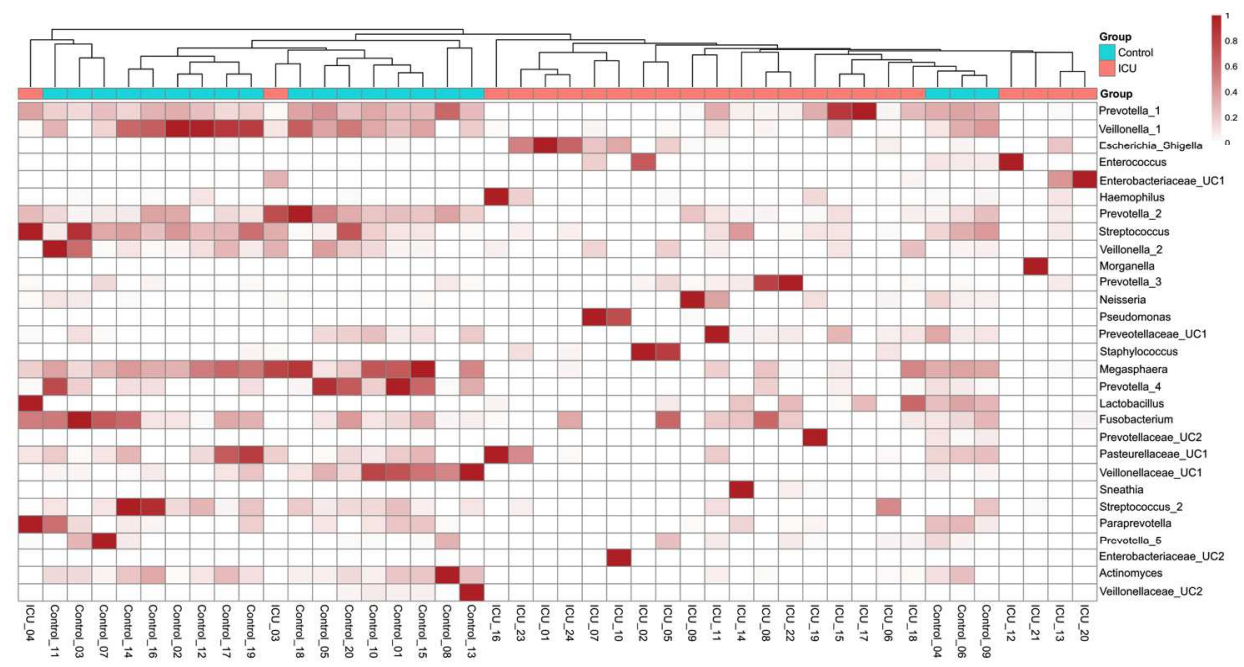

Figure 1 - ICU subglottic aspirates are characterized by reduced microbiological diversity and the presence of more species recognized as potential respiratory pathogens than control secretions. (A) Semi-quantitative bacterial and fungal culture of subglottic aspirates. (B) 16S rRNA bacterial profiling of subglottic aspirates. Observed operational taxonomic units (OTUs) and Shannon alpha diversity are demonstrated. The boxplots show the upper and lower quartiles and median, whiskers represent the range. (C) Hierarchical clustering of subglottic aspirate samples by bacterial relative abundance at OTU level. The row above the heat map shows ICU samples (orange) and control samples (blue) where each column represents a patient's sample. The 30 most abundant bacterial OTUs are displayed on the heat map. A; Mann-Whitney $U$ test, B; Kruskal-Wallis test, $* * p<0.01, * * * p<0.001(A$; ICU $n=23$, control $n=25$. B/C; ICU $n=24$, control $n=20)$.

$178 \times 126 \mathrm{~mm}(300 \times 300 \mathrm{DPI})$ 
A

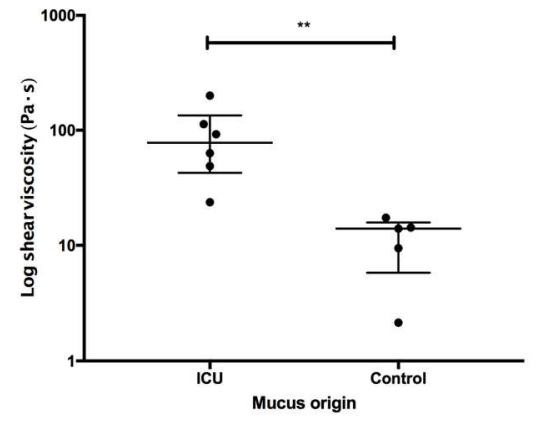

C

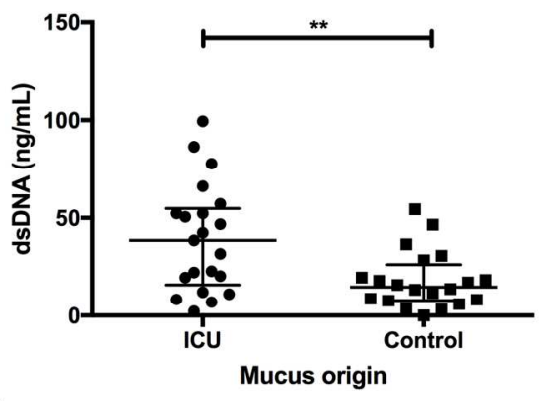

D

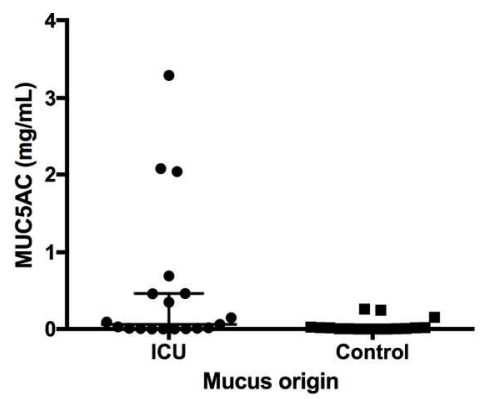

B

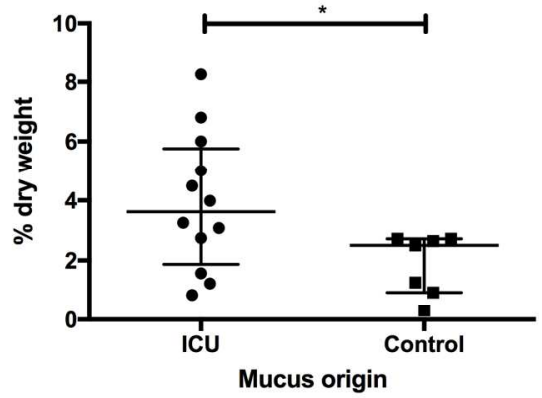

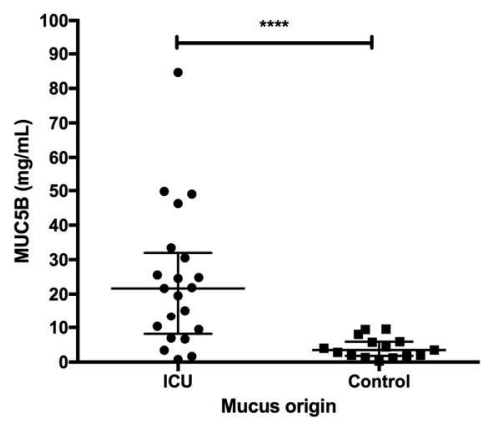

Figure 2 - ICU aspirates are more dehydrated and viscous, and contained a greater concentration of dsDNA and MUC5B, but not MUC5AC, than control mucus. (A) Mucus shear viscosity was analyzed at $37^{\circ} \mathrm{C}$. Values are expressed as pascal-seconds ( $\mathrm{Pa} \cdot \mathrm{s})$ at a shear rate of $1 \mathrm{~s}-1$. (B) Aspirates were weighed before and after dehydration overnight at $80^{\circ} \mathrm{C}$. The percentage solid was then calculated. (C) dsDNA concentration was quantified by Quant-iT assay kit. (D) Mucin MUC5B and MUC5AC concentrations were quantified by ELISA. Each dot represents a sample from an individual patient. Long horizontal bars indicate medians, shorter horizontal bars indicate interquartile range. Statistical analysis was by Mann-Whitney $\mathrm{U}$ test, $* \mathrm{p}<0.05$, $* * \mathrm{p}<0.01, * * * * \mathrm{p}<0.0001$.

$168 \times 175 \mathrm{~mm}(300 \times 300 \mathrm{DPI})$ 

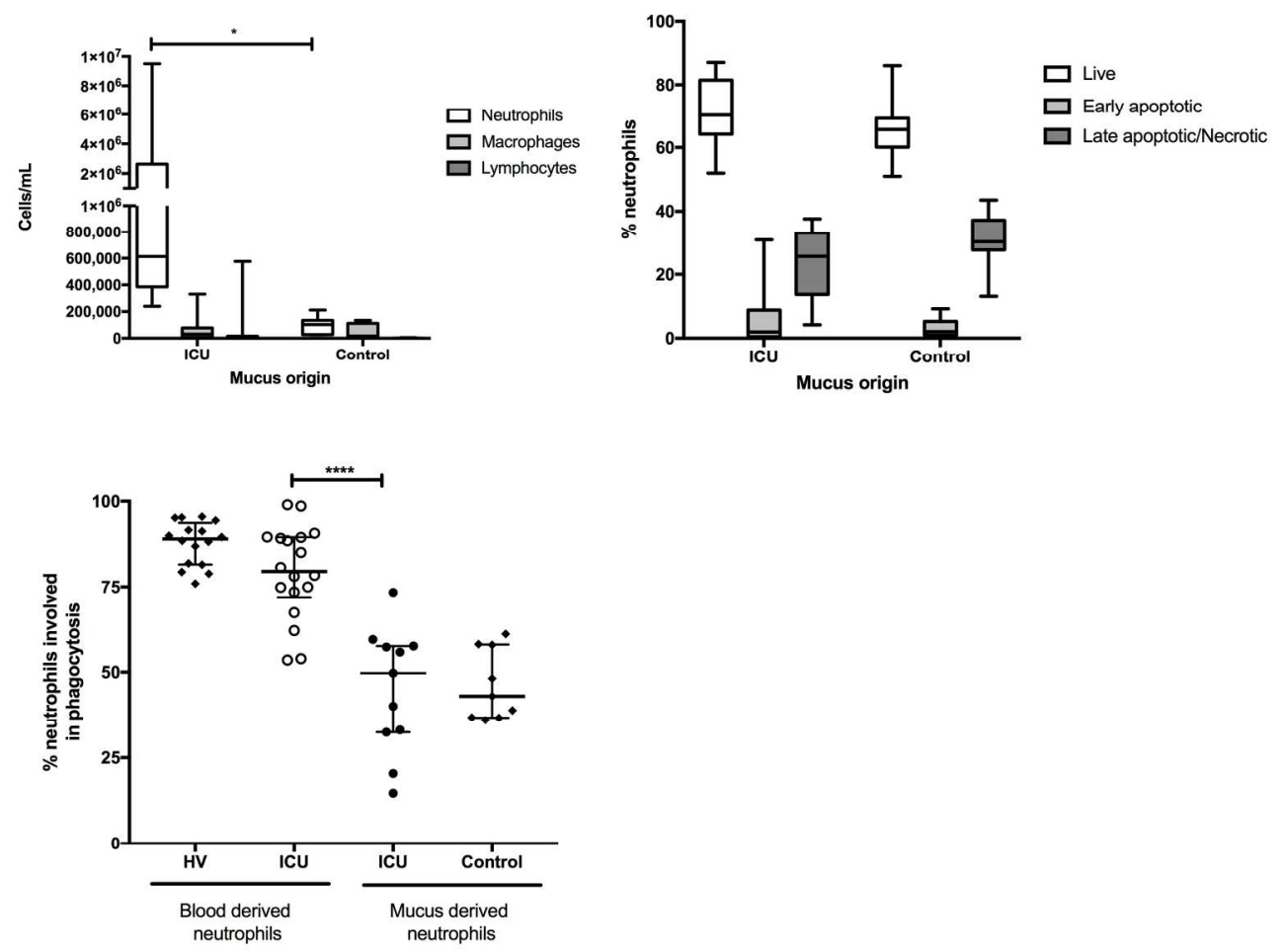

Figure 3 - ICU subglottic aspirates are dominated by high numbers of viable neutrophils, capable of phagocytosis. (A) Cells were extracted from subglottic aspirates by treatment with $0.08 \%$ DTT. Differential cell count was then performed using a hemacytometer and cytospin preparations. (B) Extracted cells were incubated with Annexin V and propidium iodide. Viable, early apoptotic and late apoptotic/necrotic cells were determined by flow cytometric gating of neutrophils. No significant difference between the two cohorts was demonstrated. (C) Cells were extracted from the whole blood of ICU patients or healthy volunteers (HV) using dextran sedimentation, or the mucus of ICU patients/control patients after treatment with $0.08 \%$ DTT.

Extracted cells were incubated at $37^{\circ} \mathrm{C}$ for 1 hour with serum-opsonized pHrodo $\AA$ green $\mathrm{S}$. aureus Bioparticles. Phagocytosis was determined by flow cytometry. A negative control sample on ice was used in all experiments. Data in A and B are presented as box and whisker plots where the horizontal line depicts the median, boxes the interquartile range and whiskers the range. In $\mathrm{C}$, each dot represents a sample from an individual. Long horizontal bars indicate medians, shorter horizontal bars indicate interquartile range. Statistical analysis was by Kruskal-Wallis test and Dunn's post hoc test, $* p<0.05, * * * * p<0.0001$ (A; ICU n $=18$, control $n=7$. B; ICU $n=18$, control $n=8$ ).

$190 \times 144 \mathrm{~mm}(300 \times 300 \mathrm{DPI})$ 

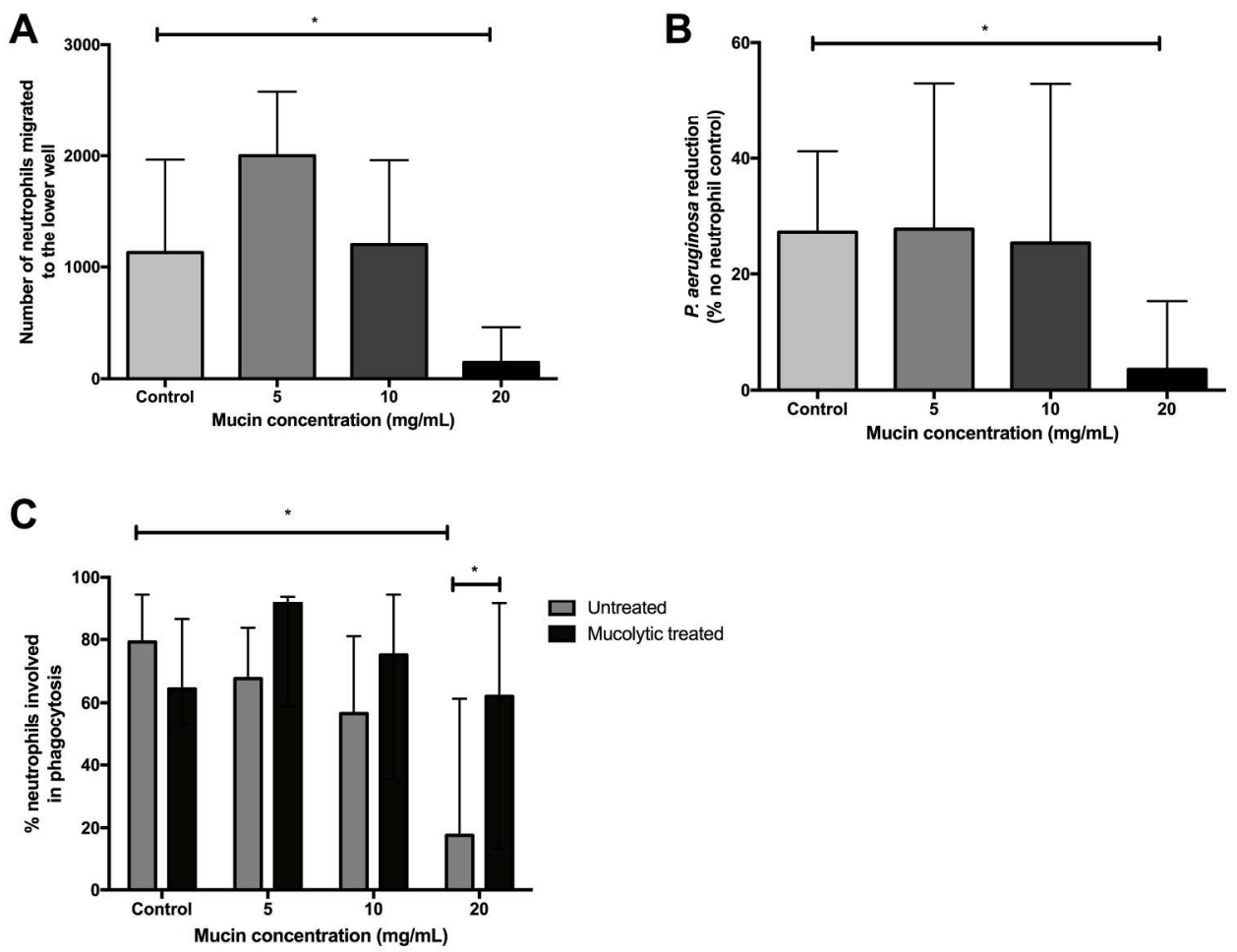

Figure 4 - Purified ICU-derived mucin inhibits neutrophil function and this effect is reversible with mucolytic treatment. (A) Neutrophil chemotaxis was measured using carboxyfluorescein succinimidyl ester (CFSE)labeled neutrophils incubated within a transwell insert ( $3.0 \mu \mathrm{m}$ pore size). The number of neutrophils that migrated from the apical compartment to the lower compartment (containing IL-8 at $10 \mathrm{ng} / \mathrm{mL}$ ) at $3 \mathrm{hours}$ was established. (B) Bacterial killing was determined using P. aeruginosa PA01 (opsonized using serum from the same donor who provided neutrophils) incubated with neutrophils for 30 minutes. Serial dilution on agar plates was performed, and colonies counted at 24 hours to derive a percentage reduction in colony forming units (CFU), measured against a sample without neutrophils. (C) Neutrophil phagocytosis pre- and postmucolytic treatment was measured. Cells were incubated in mucin for 30 minutes prior to treatment with

$0.08 \%$ dithiothreitol (DTT) for 5 minutes, centrifuged and re-suspended in a solution without mucin.



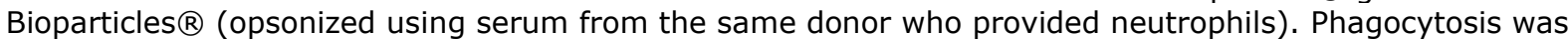
determined by flow cytometric gating of viable neutrophils with ingested particles versus a control sample on ice. Data are expressed as median and 95\% confidence interval. Kruskal-Wallis test and Dunn's post hoc test were used to compare the differences against the control without mucin. ${ }^{*} p<0.05 .(A ; n=6, B ; n=5$; C $n=6)$. 
A

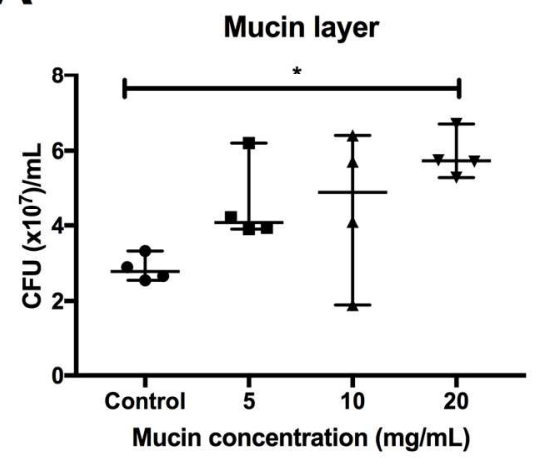

B

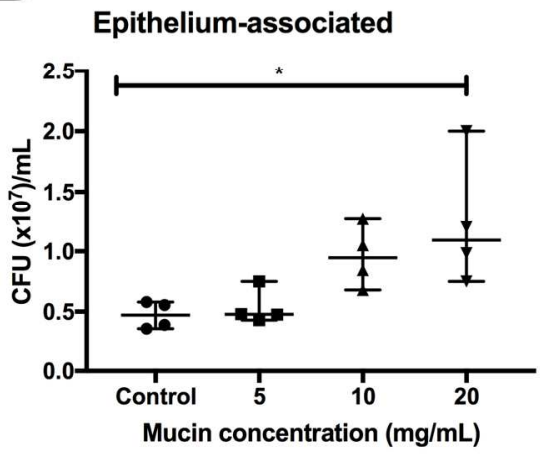

Figure 5 - Purified subglottic mucin from ICU patients increases bacterial growth and invasion in bacterialepithelial co-culture experiments. The mucus layer of PSECs cultured at ALI was removed and replaced with $50 \mu \mathrm{L}$ of purified ICU-derived mucin $(0,5,10$ and $20 \mathrm{mg} / \mathrm{mL})$, and incubated for 1 hour $\left(37^{\circ} \mathrm{C} 5 \% \mathrm{CO} 2\right)$. P.

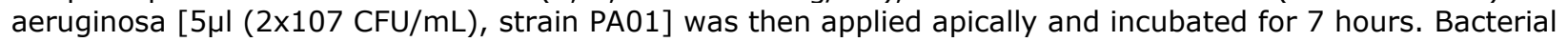
growth in the mucin layer (A) and epithelial homogenate (B) was determined by serial dilution on agar plates, counting colony-forming units (CFU) at 24 hours. Data are expressed as median and $95 \% \mathrm{CI}$. Kruskal-Wallis test and Dunn's post hoc test were used to compare samples and the control without mucin, $* \mathrm{p}<0.05, \mathrm{n}=4$.

$166 \times 68 \mathrm{~mm}(300 \times 300 \mathrm{DPI})$ 
Excess mucin impairs subglottic epithelial host defense in mechanically ventilated patients

Jason Powell ${ }^{1}$, James Garnett ${ }^{1}$, Michael W Mather ${ }^{1}$, Faye A H Cooles ${ }^{1}$, Andrew Nelson ${ }^{2}$, Bernard Verdon $^{3}$, Jon Scott ${ }^{1}$, Kasim Jiwa ${ }^{1}$, Marie-Hélène Ruchaud-Sparagano ${ }^{1}$, Stephen P Cummings ${ }^{4}$, John Perry ${ }^{5}$, Stephen E Wright ${ }^{6}$, Janet A Wilson ${ }^{7}$, Jeffrey Pearson ${ }^{2}$, Chris Ward $^{1 *}$, A John Simpson ${ }^{1 *} *$ equal contribution made 


\section{SUPPLEMENTARY METHODS}

\section{Patients and volunteers}

ICU patients fulfilled the criteria described in the main paper. Exclusion criteria comprised age $<18$ years, known current or previous malignancy or radiotherapy to the upper aerodigestive tract, $\mathrm{PaO}_{2}<8 \mathrm{kPa}$ on $\mathrm{FiO}_{2}>0.7$, positive end-expiratory pressure $>15 \mathrm{cmH}_{2} \mathrm{O}$, peak airway pressure $>30 \mathrm{cmH}_{2} \mathrm{O}$, heart rate $>140$ beats per minute, mean arterial pressure $<60 \mathrm{mmHg}$, bleeding diathesis (including platelet count $<20 \times 10^{9}$ per liter of blood or prothrombin time or activated partial thromboplastin time greater than 1.5 times the reference range) and poorly controlled intracranial pressure $(>20 \mathrm{mmHg}$ if measured).

Controls were recruited from elective theater lists of patients undergoing laryngeal examination under general anesthesia. Exclusion criteria comprised age $<18$ years, known current or previous malignancy or radiotherapy to the upper aerodigestive tract, abnormal subglottic/laryngeal mucosal appearances at clinic appointment or theater examination.

Healthy volunteers (HV) were recruited from university staff, students and the general population as a control group allowing comparison with ICU blood-derived neutrophil phagocytosis levels. We recruited $16 \mathrm{HV}$, median age 67 (range 23 - 89) years, 50\% were male. There was no significant difference in the age or sex distribution between these volunteers and the ICU cohort, $\mathrm{p}=0.54^{*}$ and $\mathrm{p}=0.43^{\dagger}$ respectively. "Mann-Whitney U test, ${ }^{\dagger}$ by Chi Squared test.

A separate group of $\mathrm{HV}$ was recruited from university staff, students and the general population to provide blood to generate healthy neutrophils for in vitro experiments. 


\section{Collection of subglottic secretions, subglottic brushings and blood}

Eligible patients had subglottic secretions and brushings performed by a single experienced operator. Briefly, secretions were suctioned under direct vision from the subglottic region via a bronchoscope or laryngoscope. If subglottic secretion drainage (SSD) was being used (in the ICU patients), additional secretions were taken via this route. In control patients subglottic mucosal brushing was performed via the laryngoscope or bronchoscope. Whole blood was collected into $0.38 \%$ sodium citrate (final concentration).

\section{Processing of subglottic aspirates and whole blood}

If sufficient aspirate volumes were recovered a proportion was immediately frozen at $-80^{\circ} \mathrm{C}$ until further analysis. The remainder was used fresh for leukocyte extraction and quantification. Aspirates were treated with $0.08 \%$ dithiothreitol (DTT) for 5 minutes to extract cells. Aspirates were then washed and passed through a 30-micron filter. Differential cell counts were performed using a hemocytometer. An experienced pathology technician analyzed and interpreted fixed, Giemsa-stained cytospin preparations.

Citrated whole blood was separated into purified leukocytes, plasma and serum. Briefly, serum was prepared by adding $1 \mathrm{M}$ calcium chloride to plasma. Leukocytes were isolated by dextran sedimentation and discontinuous Percoll gradient separation.

\section{Bacterial identification in subglottic aspirates}

Semi-quantitative microbiology culture was performed by standardized microbiology culture techniques. In brief, samples were mixed with $0.5 \mathrm{~mL} 0.1 \%$ DTT solution and incubated for 30 minutes followed by serial dilutions in $0.85 \%$ saline. Samples were then cultured at $37^{\circ} \mathrm{C}$ for 48 hours on: 1) chocolate agar incubated in air plus $5 \% \mathrm{CO}_{2} ; 2$ ) fastidious anaerobe agar 
incubated anaerobically; 3) Sabouraud agar incubated in air. Colony types were then quantified and identified using matrix-assisted laser desorption/ionization time-of-flight mass spectrometry (MALDI-TOF MS).

Nucleic acid extraction from subglottic aspirates was carried out using PowerLyzer PowerSoil ${ }^{\circledR}$ DNA Isolation Kit (MoBio, CA, USA) in accordance with the manufacturer's instructions. Bacterial profiling utilized the $16 \mathrm{~S}$ rRNA gene targeting variable region four based on the Schloss wet-lab MiSeq standard operating procedure (SOP) and resulting raw fastq data were processed using Mothur (version 1.31.2). Paired reads were merged and processed to remove sequences containing ambiguous bases, homopolymers $>8 \mathrm{bp}$ and sequences with a length $>275 \mathrm{bp}$. Sequences were aligned to the SILVA database and chimeras were removed. The remaining sequences were classified using the RDP database and sequences not identified as bacteria were removed from the downstream analysis. Operational taxonomic units (OTUs) present in polymerase chain reaction (PCR) negative controls were removed and the positive control was removed. Reads were normalized by subsampling to 1270 reads per sample. Analysis and visualization of microbiome communities was conducted in $\mathrm{R}$ utilizing the phyloseq package.

Quantification of inflammatory cytokines, complement factors, mucins, DNA, neutrophil proteases and the physical properties of subglottic aspirates

Quantification of cytokines was performed by Meso Scale Discovery (MSD) technology using the V-PLEX Proinflammatory Panel 1 (human) kit. Quantification of IL-8 and GMCSF was performed separately using a U-PLEX kit (Meso Scale Diagnostics, MD, USA). Human neutrophil elastase was measured using Human PMN Elastase ELISA (Abcam, MA, USA). Double-stranded DNA was measured using a Quant-iT dsDNA fluorometric assay kit 
(Thermofisher, MA, USA). The Cytometric Bead Array (CBA) Human Anaphylatoxin Kit (BD, NJ, USA) was utilized to quantify C5a, and its des-Arg derivative. Analysis was performed on a calibrated FACSCanto II flow cytometer (BD Biosciences, NJ, USA). All assays were performed according to the manufacturer's instructions.

\section{Neutrophil viability}

Neutrophils were re-suspended in Annexin $\mathrm{V}$ buffer for 15 minutes on ice with allophycocyanin (APC)-conjugated Annexin V and propidium iodide (Thermofisher, MA, USA). A control tube contained unstained cells. Data were acquired immediately on a calibrated FACSCanto II flow cytometer (BD Biosciences, NJ, USA).

\section{Phagocytosis of pHrodo ${ }^{\circledR}$ Green Staphylococcus aureus Bioparticles ${ }^{\circledR}$ by neutrophils}

pHrodo ${ }^{\circledR}$ Green $S$. aureus Bioparticles ${ }^{\circledR}$ (Thermofisher, MA, USA) were opsonized by incubation at a 1:10 dilution in 50\% Iscove's Modified Dulbecco's Medium (IMDM, Thermofisher, MA, USA) / 50\% serum (from the same donor providing the neutrophils for any given experiment), for 30 minutes at $37^{\circ} \mathrm{C}$. Bioparticles were then incubated with neutrophils for 90 minutes (end particle concentration $1 \mu \mathrm{g} / \mathrm{mL}$ ). A sample was kept on ice acting as a "no phagocytosis" control. Cells were washed and data were acquired immediately on a calibrated FACSCanto II flow cytometer (Becton Dickinson Biosciences, NJ, USA), gating for viable neutrophils with ingested particles, against the no phagocytosis control.

\section{Killing of Pseudomonas by neutrophils}

Pseudomonas aeruginosa (strain PA01) was cultured overnight in Roswell Park Memorial Institute-1640 (RPMI) medium at $37^{\circ} \mathrm{C}$. Optical density measurements were used to yield a 
concentration of approximately $2 \times 10^{7}$ colony forming units $(\mathrm{CFU}) / \mathrm{mL}$ (confirmed by serial dilutions and incubation on LB agar plates). Bacteria were opsonized with $10 \%$ serum (from the same donor who provided neutrophils for any given experiment) for 30 minutes prior to co-culture with whole blood-derived neutrophils $\left(1 \times 10^{7}\right.$ cells per $\left.\mathrm{mL}\right)$ in ICU-derived mucin (in Hanks' Balanced Salt solution with $\mathrm{Ca}^{2+}$ and $\mathrm{Mg}^{2+}$ (HBSS)) for 30 minutes $\left(37^{\circ} \mathrm{C} 5 \%\right.$ $\mathrm{CO}_{2}$ ). Subsequently the samples were incubated in $0.08 \% \mathrm{DTT} / 0.01 \%$ Triton $\mathrm{X}-100$ for 30 minutes. Bacterial viability was determined by serial dilution and incubation on LB agar plates. Plates were incubated for 24 hours at $37^{\circ} \mathrm{C}$ and $\mathrm{CFU}$ counted. A control sample without neutrophils was used to determine neutrophil-specific bacterial killing.

\section{Neutrophil chemotaxis}

Carboxyfluorescein succinimidyl ester (CFSE)-stained whole blood-derived healthy volunteer neutrophils $\left(1 \times 10^{7}\right.$ cells per $\left.\mathrm{mL}\right)$ were incubated $\left(37^{\circ} \mathrm{C} 5 \% \mathrm{CO}_{2}\right)$ in the upper chamber of a transwell permeability support (3.0 $\mu \mathrm{m}$ pore size, Corning, NY, USA). Cells that had migrated into the lower chamber, containing reconstituted IL-8 solution $(10 \mathrm{ng} / \mathrm{mL}$, Sigma-Aldrich, Dorset, UK), were quantified at 3 hours, using a confocal fluorescent camera (Axio Imager II, Zeiss, Oberkochen, Germany) and automated software utilizing the JOBS module of NIS Elements (Nikon, Tokyo, Japan). A control sample comprised a well without IL-8-containing solution.

\section{Mucus analysis and mucin purification}

Shear viscosity of mucus was analyzed at $37^{\circ} \mathrm{C}$ using a Kinexus Pro (Malvern Instruments, Worcester, UK) with $60 \mathrm{~mm}$ parallel plates, according to the manufacturer's instructions. A table of shear rates was produced over the range of $0-100 \mathrm{~s}^{-1}$. Analysis was performed on rSpace software (version 1.6, Malvern Instruments, Worcester, UK). 
The percentage dry weight of mucus was calculated by using a microbalance to compare weight before and after drying the sample at $80^{\circ} \mathrm{C}$ overnight.

MUC5AC and MUC5B protein expression was measured using ELISA. A volume of $100 \mu \mathrm{L}$ of each sample was incubated in a 96-well plate at room temperature overnight. Plates were washed three times with PBS containing $0.05 \%$ Tween 20 and blocked with $1 \%$ casein for 2 hours at room temperature. Plates were again washed three times with PBS and then incubated with $100 \mu \mathrm{L}$ of primary monoclonal antibody for MUC5AC (45M1 mouse antihuman MUC5AC (Abcam, MA, USA)), diluted 1/100 in antibody diluent $(0.1 \%$ casein/0.05\% Tween 20 in PBS)) or $100 \mu \mathrm{L}$ of primary monoclonal antibody for MUC5B (EPR6920, rabbit anti-human MUC5B (Abcam, MA, USA)), diluted 1/200 in antibody diluent $(0.1 \%$ casein/0.05\% Tween 20 in PBS $))$ and incubated for 2 hours. $100 \mu \mathrm{L}$ of secondary antibody was added and incubated for 2 hours (horseradish peroxidase-conjugated goat anti-mouse/rabbit (Dako, CA, USA)), diluted 1/5000 with antibody diluent). Finally 100 $\mu \mathrm{L}$ of peroxidase substrate ABTS (2,2'-azino-bis(3-ethylbenzthiazoline-6-sulphonic acid)) was added and the plate allowed to develop. Absorbance at $405 \mathrm{~nm}$ was measured.

Individual subglottic aspirates, derived from ICU patients, were pooled and mixed with an equal volume of an enzyme inhibitor buffer cocktail, homogenized and centrifuged at $10,000 \mathrm{~g}$, for 1 hour at $4^{\circ} \mathrm{C}$. Mucin fractions were purified by cesium chloride densitygradient centrifugation (starting density $1.42 \mathrm{~g} / \mathrm{mL}$ ) in a T-1170 ultracentrifuge (Centricon, USA) at $100,000 \mathrm{~g}$, for 48 hours at $4^{\circ} \mathrm{C}$. Mucin-containing fractions were then recovered and extensively dialyzed against distilled water for 72 hours. Fractions were lyophilized for 72 
hours using a vacuum freeze dryer (Shanghai Bilon Instrument, Shanghai, China) and stored at $-20^{\circ} \mathrm{C}$ for future use.

\section{Primary subglottic epithelial cell (PSEC) culture and characterization}

PSECs were obtained from subglottic brushing samples taken from newly intubated theater attender controls. In brief, brushings were plated in serum-free Bronchial Epithelial Basal Medium (Lonza, Basel, Switzerland) supplemented with SingleQuots ${ }^{\mathrm{TM}}$ (Lonza, Basel, Switzerland) and antibiotics. Once $70-90 \%$ confluent, cells were passaged onto transwell inserts $(0.4 \mu \mathrm{m}$ pore size, Corning, NY, USA) and grown at air-liquid interface (ALI). Cells were studied 3-4 weeks post-seeding.

Epithelial characteristics were confirmed by (a) light microscopic assessment for the presence of apical cilia and (b) trans-epithelial electrical resistance, measured using an epithelial voltohmmeter (World Precision Instruments, FL, USA), according to the manufacturer's instructions.

A subset of samples underwent further characterization, including scanning electron microscopy of glutaraldehyde-fixed ALI cultures embedded in resin, performed using a Cambridge Steroscan 240 electron microscope. Cytokeratin staining was performed on methanol-fixed and permeabilized ALI cultures, using monoclonal anti-cytokeratin (panreactive) antibody (raised in mouse), conjugated with Alexa Fluor ${ }^{\circledR} 647$ (Biolegend, CA, USA), counter-stained with DAPI (4',6-diamidino-2-phenylindole dihydrochloride) nuclear stain. Imaging was performed with a confocal fluorescent camera (Axio Imager II, Zeiss, Oberkochen, Germany). 
Paraffin-embedded blocks and sections were also prepared. Briefly, ALI cultures were washed and then fixed with $4 \%$ paraformaldehyde for 20 minutes at room temperature. Subsequently the membrane was dehydrated through graded alcohols, submerged in xylene (VWR, Lutterworth, UK) for 20 minutes, twice, and then embedded in paraffin for 1 hour at $60^{\circ} \mathrm{C}$. Sections of the paraffin blocks were then cut to $5 \mu \mathrm{m}$ thickness using a microtome. Sections were later de-waxed and stained in freshly filtered Carrazzi's Haematoxylin (Thermofisher, MA, USA) for 1 minute, then counterstained with Eosin Y (Fisher Scientific, UK) for 2 minutes and dehydrated back through graded alcohols and xylene. The sections were then mounted with DPX (VWR, Lutterworth, UK) and analyzed using light microscopy.

\section{Bacterial-epithelial co-culture experiments}

PSECs were cultured at ALI in antibiotic-free medium for at least 24 hours prior to experimentation. The mucus layer on the PSECs was removed (by aspiration and washing) and replaced with $50 \mu \mathrm{L}$ of purified ICU-derived mucin in HBSS, and incubated for 1 hour $\left(37^{\circ} \mathrm{C} 5 \% \mathrm{CO}_{2}\right)$. P. aeruginosa $\left[5 \mu 1\left(2 \times 10^{7} \mathrm{CFU} / \mathrm{mL}\right), \mathrm{PA} 01\right]$ was then applied to the apical surface of the cells and incubated for 7 hours $\left(37^{\circ} \mathrm{C} 5 \% \mathrm{CO}_{2}\right)$. The mucin layer was then removed by repeated washing. The epithelial layer was removed from the transwell insert and homogenized by repeated agitation. The samples were incubated in $0.08 \%$ DTT $/ 0.01 \%$ Triton X-100 for 30 minutes. Bacterial growth in the mucin layer and epithelial homogenate was determined by serial dilution and incubation on LB agar plates. Plates were incubated for 24 hours at $37^{\circ} \mathrm{C}$ and $\mathrm{CFU}$ counted. 


\section{SUPPLEMENTARY RESULTS}

\section{Clinical characteristics of the ICU patient population}

Table E1 provides details for the ICU patient population, including the mix of surgical and medical patients included in the study, details of the type of ETT used, duration of mechanical ventilation, APACHE II score on admission to the ICU, comorbidities, outcome, use of antimicrobials, and culture results obtained from routine clinical practice.

To investigate potential correlates between mucin concentrations in the subglottic aspirates and clinical status, total mucin concentrations in ICU subglottic aspirates were compared with various parameters. Subglottic mucin concentrations showed a weak, positive correlation with duration of intubation/mechanical ventilation and increasing age (Figure E2).

\section{Bacterial and fungal identification in subglottic aspirates}

Figure E1 (A and B) shows the variability in bacterial and fungal species/families identified by semi-quantitative bacterial/fungal culture, between ICU and control aspirates, as well as the organisms with the highest CFU count on semi-quantitative culture in each group.

Bacterial 16S rRNA gene profiling allowed construction of nonmetric multidimensional scaling (nMDS) plots, based on Bray-Curtis distances, which demonstrate the similarities between the microbial communities sampled in each aspirate. Greater similarity is seen in the bacterial communities of the control aspirates (ie the blue "control" dots are clustered more closely, Figure E1C) compared to those from the ICU. Taxonomic classification also visually represents the greater diversity and similarity of subglottic bacterial communities across the ICU and control groups (Figure 1D). The percentage abundance of communities in the 
ecosystem is demonstrated in Table E2.

\section{Neutrophil viability in purified ICU-derived mucin}

Given the distinct differences in phagocytic function and chemotaxis of neutrophils in higher mucin concentrations, we investigated if there was any difference in the proportion of neutrophils that were viable, apoptotic or necrotic, after incubation in purified ICU-derived mucin. No significant differences were found when comparing proportions in different concentrations of mucin (Figure E3). As there was a slight trend towards reduced viability at higher concentrations we included a viability marker and gated out non-viable cells in all flow cytometry-based experiments.

\section{Neutrophil mobility in purified ICU-derived mucin}

The videos in Figure E4 demonstrate that healthy blood-derived neutrophils incubated in high mucin concentrations appear unable to move.

\section{Characterization of PSECs}

To investigate potential interactions between infected mucus and the subglottic epithelium we developed a novel in vitro ALI model of human PSEC and characterized the model to determine how closely it recapitulated the in vivo environment (Figure E5). PSECs formed a cobblestone mucosa typical of airway epithelial cells (Figure E5A). An epithelial phenotype was confirmed by expression of pan-cytokeratin (Figure E5B), apical cilia were demonstrated at scanning electron microscopy (Figure E5C), and appropriate levels of trans-epithelial electrical resistance were recorded (Figure E5D). At ALI the cells demonstrated a highly differentiated pseudostratified respiratory epithelium with apical cilia (Figure E5E). 
Appropriate trans-epithelial electrical resistance is a crucial feature of a normal epithelial membrane in vivo. We therefore used Ussing chambers to confirm epithelial resistance and the presence of key respiratory epithelial channels in our in vitro PSEC cultures at ALI (Figure E6). Production of mucus is also a key respiratory epithelial function, so we obtained apical aspirates of in vitro PSEC secretions at ALI and performed ELISAs on these samples. This confirmed the presence of the two key airway mucin MUC5AC and MUC5B (Figure E7). 
Page 54 of 70

SUPPLEMENTARY TABLES 


\begin{tabular}{|c|c|c|c|c|c|c|c|c|c|c|c|c|}
\hline Participant & $\begin{array}{c}\text { Reason for } \\
\text { admission to ICU }\end{array}$ & Operations & $\begin{array}{c}\text { APACHEII } \\
\text { score }\end{array}$ & ETT & \begin{tabular}{|l|} 
ETT cuff \\
pressure \\
$(\mathrm{cmH2O})$ \\
\end{tabular} & \begin{tabular}{|c|} 
Days \\
ventilated
\end{tabular} & Co-morbidities & Antimicrobials & $\begin{array}{c}\text { VAP } \\
\text { diagnosed }\end{array}$ & $\begin{array}{c}\text { Outcome of } \\
\text { admission }\end{array}$ & $\begin{array}{c}\text { BAL } \\
\text { microbiology }\end{array}$ & $\begin{array}{c}\text { Endotracheal } \\
\text { aspirate } \\
\text { microbiology }\end{array}$ \\
\hline ICU_1 & $\begin{array}{l}\text { Post-operative } \\
\text { infection }\end{array}$ & Spinal & 29 & $\begin{array}{l}7.5 \text { Portex } \\
\text { with SSD }\end{array}$ & 26 & 5 & $\begin{array}{c}\text { COPD, HTN, } \\
\text { hypothyroidism }\end{array}$ & Tazocin & $\mathrm{N}$ & Died & & Escherichia \\
\hline $\mathrm{ICU} \_2$ & CAP & None & 28 & 7.5 Portex & 24 & 5 & Crohn's disease & Clindamycin, Tazocin & $\mathrm{N}$ & Died & & Staphylococcus \\
\hline $\mathrm{ICU}_{-} 3$ & CAP & None & 18 & $\begin{array}{c}9 \text { Portex with } \\
\text { SSD }\end{array}$ & 20 & 4 & Quadriplegic & Tazocin & $\mathrm{N}$ & Recovered & & $\begin{array}{c}\text { Stenotrophomonas, } \\
\text { Klebsiella }\end{array}$ \\
\hline $\mathrm{ICU}_{-} 4$ & $\begin{array}{c}\text { Cerebrovascular } \\
\text { accident }\end{array}$ & Neurological & 25 & - & 26 & 6 & None & Tazocin & $\mathrm{N}$ & Long-term rehab & No growth & \\
\hline ICU_5 & $\begin{array}{l}\text { Hypoxic brain } \\
\text { injury }\end{array}$ & None & 31 & $\begin{array}{c}9 \text { Portex with } \\
\text { SSD }\end{array}$ & 24 & 4 & None & Tazocin, Metronidazole & $\mathrm{N}$ & Long-term rehab & & No growth \\
\hline ICU_6 & CAP & None & 21 & 7 Portex & 30 & 13 & Alcohol excess & $\begin{array}{c}\text { Clindamycin, } \\
\text { Meropenem, } \\
\text { Erythromycin, } \\
\text { Flucloxacillin, Tazocin }\end{array}$ & Y & Died & & No growth \\
\hline ICU_7 & $\begin{array}{l}\text { Myocardial } \\
\text { infarction }\end{array}$ & Abdominal & 21 & $\begin{array}{c}8 \text { Portex with } \\
\text { SSD }\end{array}$ & 24 & 4 & $\mathrm{IHD}$ & $\begin{array}{l}\text { Tazocin, Fluconazole, } \\
\text { Metronidazole, Tazocin }\end{array}$ & $\mathrm{N}$ & Died & Pseudomonas & \\
\hline $\mathrm{ICU} \_8$ & Head trauma & Neurological & 6 & & - & 9 & None & None & $\mathrm{N}$ & Long-term rehab & & Serratia \\
\hline ICU_9 & CAP & None & 14 & 7 Portex & 22 & 5 & $\begin{array}{c}\text { Epilepsy, } \\
\text { cerebral palsy }\end{array}$ & $\begin{array}{c}\text { Cipnofloxacin, } \\
\text { Doxycycline, } \\
\text { Metronidazole, Linezolid } \\
\text { Gentamicin }\end{array}$ & $\mathrm{N}$ & Long-term rehab & & \begin{tabular}{|c} 
Stenotrophomonas, \\
Providencia, \\
Achromobacter, \\
Pseudomonas, \\
Delftis
\end{tabular} \\
\hline ICU_10 & $\begin{array}{c}\text { Cerebrovascular } \\
\text { accident }\end{array}$ & None & 23 & $\begin{array}{c}7 \text { Portex with } \\
\text { SSD }\end{array}$ & 22 & 6 & HTN & Daptomycin & $\mathrm{N}$ & Recovered & & Serratia \\
\hline ICU_11 & Head trauma & Neurological & 27 & 8 Portex & 24 & 4 & HTN & None & $\mathrm{Y}$ & Long-term rehab & & Serratia \\
\hline ICU_12 & Pneumonitis & None & 19 & \begin{tabular}{|c|}
7.5 \\
Mallinckrodt \\
with SSD \\
\end{tabular} & 22 & 7 & $\begin{array}{l}\text { Polymyalgia } \\
\text { rheumatica }\end{array}$ & $\begin{array}{c}\text { Tazocin, Co-trimoxazole, } \\
\text { Meropenem, } \\
\text { Clarithromycin }\end{array}$ & $\mathrm{N}$ & Died & No growth & \\
\hline ICU_13 & CAP & None & 16 & $\mid \begin{array}{c}8 \text { Portex with } \\
\text { SSD }\end{array}$ & 22 & 4 & $\begin{array}{c}\text { Schizophrenia, } \\
\text { emphysema }\end{array}$ & \begin{tabular}{|c|} 
Chloramphenicol, Co- \\
amoxiclav, Co- \\
Trimoxazole
\end{tabular} & $\mathrm{N}$ & Died & Enterobacter & \\
\hline ICU_14 & $\begin{array}{c}\text { Cerebrovascular } \\
\text { accident }\end{array}$ & None & 16 & $\begin{array}{c}7 \text { Portex with } \\
\text { SSD }\end{array}$ & 20 & 4 & DM2, HTN & Cefuroxime, Fluconazole & $\mathrm{N}$ & Long-term rehab & & Staphylococcus \\
\hline ICU_15 & Encephalitis & None & 5 & $\begin{array}{l}8.5 \text { Portex } \\
\text { with SSD }\end{array}$ & 25 & 4 & $\begin{array}{c}\text { DM2, IHD, } \\
\text { alcohol excess }\end{array}$ & Aciclovir, Cefotaxime & $\mathrm{N}$ & Recovered & & No growth \\
\hline ICU_16 & Head trauma & Neurological & 14 & - & 25 & 6 & None & Co-amoxiclav & $\mathrm{N}$ & Recovered & & \\
\hline ICU_17 & $\begin{array}{c}\text { Ruptured aortic } \\
\text { aneurysm }\end{array}$ & Vascular & 19 & $\begin{array}{c}8.0 \\
\text { Mallinckrodt }\end{array}$ & 30 & 16 & DM2 & Linezolid, Ertapenem & $\mathrm{N}$ & Died & Staphylococcus & $\begin{array}{l}\text { Haemophilus, } \\
\text { Staphylococcus }\end{array}$ \\
\hline ICU_18 & Head trauma & Neurological & 15 & $\begin{array}{c}8 \text { Portex with } \\
\text { SSD }\end{array}$ & 20 & 6 & $\begin{array}{l}\text { HTN, alcohol } \\
\text { excess }\end{array}$ & $\begin{array}{c}\text { Co-amoxiclav, } \\
\text { Meropenem, Tazocin }\end{array}$ & $\mathrm{N}$ & Long-term rehab & & Proteus, Citrobacter \\
\hline ICU_19 & $\begin{array}{l}\text { Neurological } \\
\text { condition }\end{array}$ & None & 10 & $\begin{array}{l}8.5 \text { Portex } \\
\text { with SSD }\end{array}$ & 22 & 4 & None & Co-amoxiclav & $\mathrm{N}$ & Recovered & & No growth \\
\hline ICU_20 & Head trauma & None & 22 & $\mid \begin{array}{c}8 \\
\text { Mallinckrodt } \\
\text { with SSD }\end{array}$ & 24 & 5 & $\begin{array}{l}\text { IHD, non- } \\
\text { Hodgkin's } \\
\text { lymphoma, }\end{array}$ & Co-amoxiclav, Tazocin & $\mathrm{N}$ & Died & & Klebsiella \\
\hline ICU_21 & CAP & None & 18 & 7.5 Portex & 24 & 4 & HTN & $\begin{array}{l}\text { Amoxicillin, } \\
\text { Clarithromycin, } \\
\text { Cefuroxime }\end{array}$ & $\mathrm{N}$ & Died & & Candida \\
\hline ICU_22 & Head trauma & Neurological & 11 & $\begin{array}{c}8 \\
\text { Mallinckrodt } \\
\text { with SSD }\end{array}$ & 28 & 5 & $\begin{array}{l}\text { HTN, DM2, } \\
\text { alcohol excess }\end{array}$ & $\begin{array}{c}\text { Co-amoxiclav, Co- } \\
\text { trimoxale, Cefuroxime }\end{array}$ & $\mathrm{N}$ & Long-term rehab & & $\begin{array}{l}\text { Haemophilus, } \\
\text { Staphylococcus }\end{array}$ \\
\hline ICU $\_23$ & HAP & None & 32 & $\begin{array}{c}8.5 \\
\text { Mallinckrodt }\end{array}$ & 22 & 5 & Myeloma & $\begin{array}{l}\text { Aciclovir, Colistin } \\
\text { Metronidazole, } \\
\text { Neomycin, Tazocin, } \\
\text { Teicoplanin, } \\
\text { Vancomyocin }\end{array}$ & $\mathrm{N}$ & Died & & \\
\hline ICU_24 & $\begin{array}{l}\text { Hypoxic brain } \\
\text { injury }\end{array}$ & None & 17 & $\begin{array}{c}7 \text { Portex with } \\
\text { SSD }\end{array}$ & 18 & 5 & Epilepsy & $\begin{array}{l}\text { Meropenem, } \\
\text { Clotrimazole }\end{array}$ & $\mathrm{N}$ & Recovered & Pseudomonas & $\begin{array}{c}\text { Escherichia, } \\
\text { Stenotrophomonas }\end{array}$ \\
\hline
\end{tabular}




\section{Table E1. Clinical details of ICU patients.}

APACHE II score was calculated at the time of admission to ICU. The 3 right hand columns refer to samples obtained as part of routine clinical care (ie separate to this study); a blank cell indicates no sample was sent. VAP diagnosis was made by the clinical team. In the ETT column, - indicates information unavailable. Antimicrobials listed include agents used at the time of subglottic aspiration or during the ICU admission prior to sampling.

APACHE, Acute Physiology and Chronic Health Evaluation; BAL, bronchoalveolar lavage; CAP, community-acquired pneumonia; COPD, chronic obstructive pulmonary disease; DM2, type 2 diabetes mellitus; ETT, endotracheal tube; HAP, hospital-acquired pneumonia; HTN, hypertension; ICU, intensive care unit; IHD, ischemic heart disease; SSD, subglottic secretion drainage; VAP, ventilator-associated pneumonia. 


\begin{tabular}{|c|c|c|c|}
\hline & & Relative abu & ndance (\%) \\
\hline Taxa & FDR-Adj. P & Mean of Control & Mean of ICU \\
\hline Actinomyces & 0.000007471 & 1.29 & 0.07 \\
\hline Veillonellaceae_unclassified & 0.000084855 & 2.69 & 0.03 \\
\hline Veillonella & 0.000126457 & 18.01 & 1.21 \\
\hline Streptococcus & 0.000126457 & 1.68 & 0.23 \\
\hline Streptococcus & 0.000126457 & 1.01 & 0.17 \\
\hline Campylobacter & 0.000126457 & 0.68 & 0.04 \\
\hline Rothia & 0.000126457 & 0.43 & 0.12 \\
\hline TM7_genus_incertae_sedis & 0.000126457 & 0.49 & 0.01 \\
\hline Selenomonas & 0.000317446 & 0.82 & 0.05 \\
\hline Megasphaera & 0.000451107 & 3.20 & 0.64 \\
\hline Leptotrichia & 0.001830059 & 0.79 & 0.01 \\
\hline Prevotella & 0.002455293 & 4.80 & 1.36 \\
\hline Veillonellaceae_unclassified & 0.002455293 & 1.41 & 0 \\
\hline Veillonella & 0.002455293 & 0.96 & 0 \\
\hline Oribacterium & 0.002455293 & 0.19 & 0.05 \\
\hline Prevotella & 0.002679397 & 3.79 & 0.21 \\
\hline Lachnospiraceae_unclassified & 0.002679397 & 0.23 & 0.01 \\
\hline Granulicatella & 0.003104225 & 0.34 & 0.08 \\
\hline Gemella & 0.003116766 & 0.39 & 0.20 \\
\hline Streptococcus & 0.005361409 & 4.03 & 1.37 \\
\hline Prevotella & 0.007894449 & 23.39 & 11.93 \\
\hline Leptotrichia & 0.012684256 & 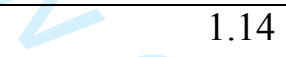 & 0.07 \\
\hline Lachnospiraceae_unclassified & 0.017543293 & 0.32 & 0.07 \\
\hline Fusobacterium & 0.022312655 & 2.10 & 0.89 \\
\hline Selenomonas & 0.022312655 & 0.53 & 0.21 \\
\hline Anaeroglobus & 0.025712556 & 0.28 & 0.22 \\
\hline Prevotella & 0.029567233 & 0.40 & 0.09 \\
\hline Lactobacillus & 0.031428462 & 0.02 & 2.12 \\
\hline Paraprevotella & 0.031428462 & 0.99 & 0.54 \\
\hline Mycoplasma & 0.031428462 & 0.02 & 0.52 \\
\hline Enterococcus & 0.031946906 & 0 & 7.37 \\
\hline Oribacterium & 0.039017981 & 0.22 & 0.03 \\
\hline Pasteurellaceae_unclassified & 0.040297793 & 1.83 & 0.87 \\
\hline Veillonella & 0.040982332 & 4.55 & 1.28 \\
\hline Staphylococcus & 0.044489587 & 0.08 & 3.12 \\
\hline
\end{tabular}


Table E2. Subglottic aspirates were processed using $16 \mathrm{~S}$ rRNA bacterial profiling. Significantly distinct operational taxonomic units (OTUs) with percentage abundance per group. Statistical analysis by Mann-Whitney $U$ test adjusted for false discovery rate (FDR). ICU $n=24$, control $n=20$. 


\section{SUPPLEMENTARY FIGURE LEGENDS}

\section{Figure E1}

(A) Subglottic aspirates underwent semi-quantitative bacterial/fungal culture. The number of samples containing each genus/family was recorded. Significant results are demonstrated for each genus (Streptococcus, Rothia, Actinomyces, Candida, Enterococcus). The family Enterobacteriaceae was also included due to the number of different individual species recovered. (B) The organism with the highest CFU count was recorded. Significant results are demonstrated for the genus (Streptococcus) and family (Enterobacteriaceae). (C) Subglottic aspirates were processed using 16S rRNA bacterial profiling. Nonmetric multidimensional scaling (nMDS) plots based on Bray-Curtis distances were generated. The two most distinct taxonomic variables are plotted as correlations with control and ICU samples. (D) Taxonomic classification of bacterial reads demonstrating the 20 most common operational taxonomic units (OTUs). A/B; Fisher's exact test, D; Mann-Whitney U test, ${ }^{*} \mathrm{p}<0.05,{ }^{* *} \mathrm{p}<0.01$, $* * * \mathrm{p}<0.001 * * * * \mathrm{p}<0.0001(\mathrm{~A} / \mathrm{B} ; \mathrm{ICU} \mathrm{n}=23$, control $\mathrm{n}=25, \mathrm{C} / \mathrm{D} ;$ ICU $\mathrm{n}=24$, control $\mathrm{n}=$ 20). 


\section{Figure E2}

Increased total mucin concentration in subglottic aspirates is associated with length of intubation and mechanical ventilation, and age. Total mucin concentrations (MUC5B and MUC5AC) in ICU aspirates were correlated with clinical parameters of length of continuous intubation and mechanical ventilation at the time of sampling $(A)$ and the patient's age $(B)$. Data were analyzed by linear regression. 


\section{Figure E3}

Whole blood-derived neutrophils from healthy volunteers were incubated at $37^{\circ} \mathrm{C}$ in purified mucin (from ICU patients) for 1 hour prior to flow cytometric analysis of viability using Annexin V (Ann V) and propidium iodide (PI). (A) Data are expressed as median and 95\% CI. Kruskal-Wallis test and Dunn's post hoc test were used to compare the differences against the control without mucin. No significant differences were observed. (B) Representative flow cytometry plot showing viable cells (Ann V negative, PI negative [Q3]), early apoptotic cells (Ann V positive, PI negative [Q1]), and the mixed population of late apoptotic and necrotic cells (PI positive [Q2 and Q4]). (C) Representative flow cytometry plot showing neutrophil phagocytosis as determined by pHrodo ${ }^{\circledR}$ Green $S$. aureus Bioparticles ${ }^{\circledR}$. A sample was kept on ice acting as a "no phagocytosis" control. Gating was performed to determine the percentage of neutrophils with ingested particles, against the no phagocytosis control. SSC, Side Scatter. 


\section{Figure E4}

CFSE-stained whole blood-derived neutrophils from healthy volunteers were incubated in a 96-well plate at $37^{\circ} \mathrm{C}$ containing purified ICU-derived mucin. Video (A) contained no mucin and video $(B)$ contained mucin $20 \mathrm{mg} / \mathrm{mL}$. 


\section{Figure E5}

(A) Submerged culture of human PSECs, with a typical cobblestone appearance on light microscopy. (B) Same sample after passage and air-liquid interface (ALI) culture. Epithelial phenotype was confirmed by expression of pan-cytokeratin (red fluorescence) and nuclei counterstained with DAPI (blue). (C) Trans-epithelial electrical resistance measurements across epithelial cells at ALI. Horizontal line represents median value. Images are representative of 9 separate experiments. (D) Scanning electron micrograph of epithelial cells at ALI demonstrating apical cilia. (E) Brightfield micrograph image of a cross-section of cells at ALI culture (paraffin-embedded), demonstrating highly differentiated pseudostratified respiratory epithelium (including basal, ciliated, and goblet cells) supported on a transwell membrane. 


\section{Figure E6}

Ussing chamber studies demonstrate the electrophysiological properties of PSECs at ALI over time. Human PSECs grown on Snapwells $\left(37^{\circ} \mathrm{C} 5 \% \mathrm{CO}_{2}\right)$ were assessed in an Ussing chamber. Short-circuit current (Isc) values reflect anion $\left(\mathrm{Cl}^{-}\right)$secretion and/or cation absorption $\left(\mathrm{Na}^{+}\right)$. Exposure of the epithelium to $10 \mu \mathrm{M}$ amiloride (AMIL) blocked the apical epithelial sodium channels $(\mathrm{ENaC})$ in the polarized epithelial cells. $10 \mu \mathrm{M}$ forskolin (FSK) was then added to activate cAMP cascades and caused a significant elevation in whole epithelial current. $20 \mu \mathrm{M}$ inh172, a specific cystic fibrosis transmembrane conductance regulator (CFTR) inhibitor, reversed this elevated Isc current, which demonstrated that the majority of the forskolin response was attributable to CFTR. Resistance was monitored by applying $5 \mathrm{mV}$ voltage pulses at 30 second intervals and monitoring the change in Isc (not shown). The resistance was multiplied by the surface area of the transwell, to give an electrical resistance value in $\Omega . \mathrm{cm}^{2}$. Resistance values shown are initial measurements. Data from one representative experiment. 


\section{Figure E7}

Apical secretions collected from PSECs at ALI, demonstrating airway mucins MUC5B and MUC5AC. Mucin concentrations were quantified from apical aspirates and measured by ELISA. Horizontal bars depict median values, $\mathrm{n}=11$ MUC5B, $\mathrm{n}=9$ MUC5AC. 
A

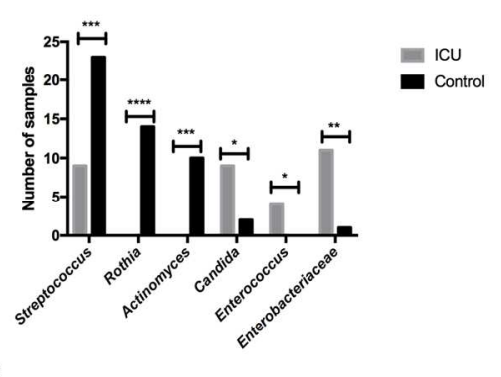

B

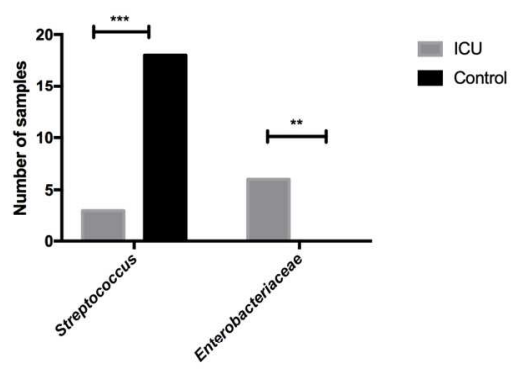

C

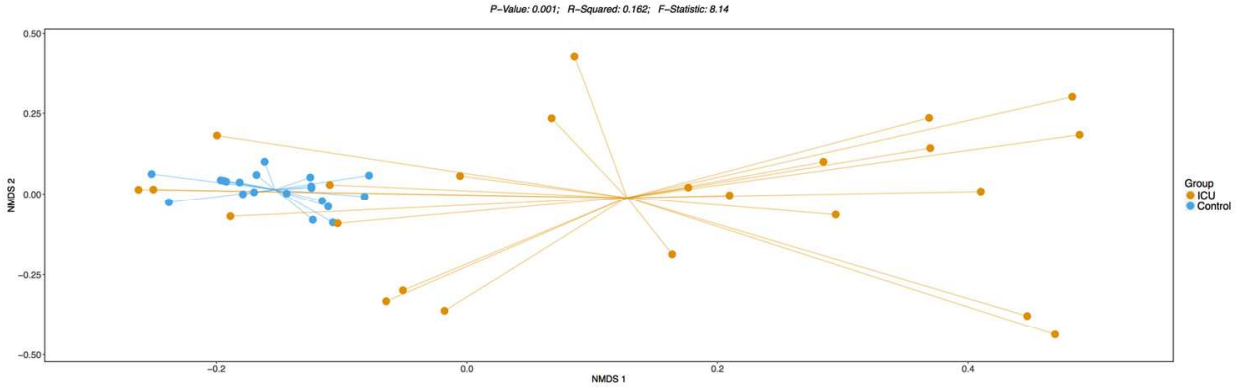

D

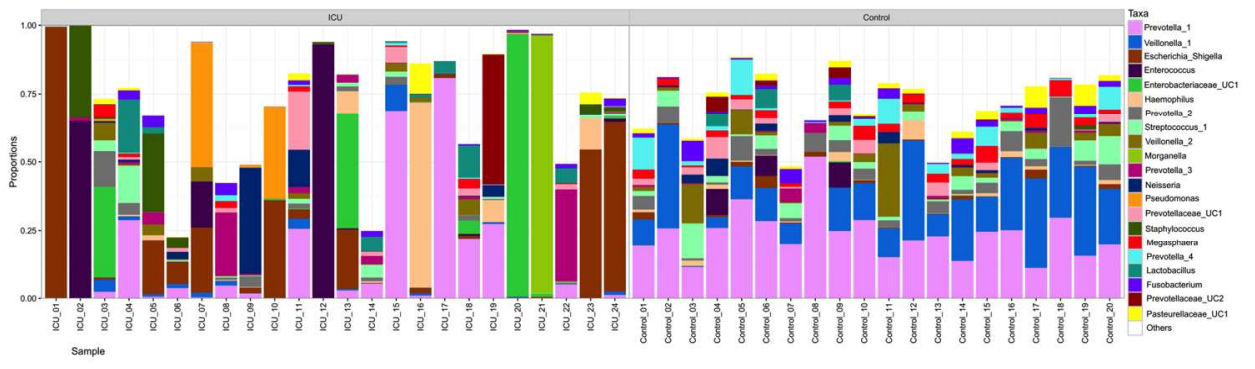

Figure E1 - (A) Subglottic aspirates underwent semi-quantitative bacterial/fungal culture. The number of samples containing each genus/family was recorded. Significant results are demonstrated for each genus

(Streptococcus, Rothia, Actinomyces, Candida, Enterococcus). The family Enterobacteriaceae was also included due to the number of different individual species recovered. (B) The organism with the highest CFU count was recorded. Significant results are demonstrated for the genus (Streptococcus) and family

(Enterobacteriaceae). (C) Subglottic aspirates were processed using 16S rRNA bacterial profiling. Nonmetric multidimensional scaling (nMDS) plots based on Bray-Curtis distances were generated. The two most distinct taxonomic variables are plotted as correlations with control and ICU samples. (D) Taxonomic classification of bacterial reads demonstrating the 20 most common OTUs. A/B; Fisher's exact test, D; Mann-Whitney U test, ${ }^{*} \mathrm{p}<0.05, * * \mathrm{p}<0.01, * * * \mathrm{p}<0.001 * * * * \mathrm{p}<0.0001$ (A; ICU $\mathrm{n}=23$, control $\mathrm{n}=15, \mathrm{~B}$; ICU $n=19$, control $n=24, C / D ;$ ICU $n=24$, control $n=20$ ). 


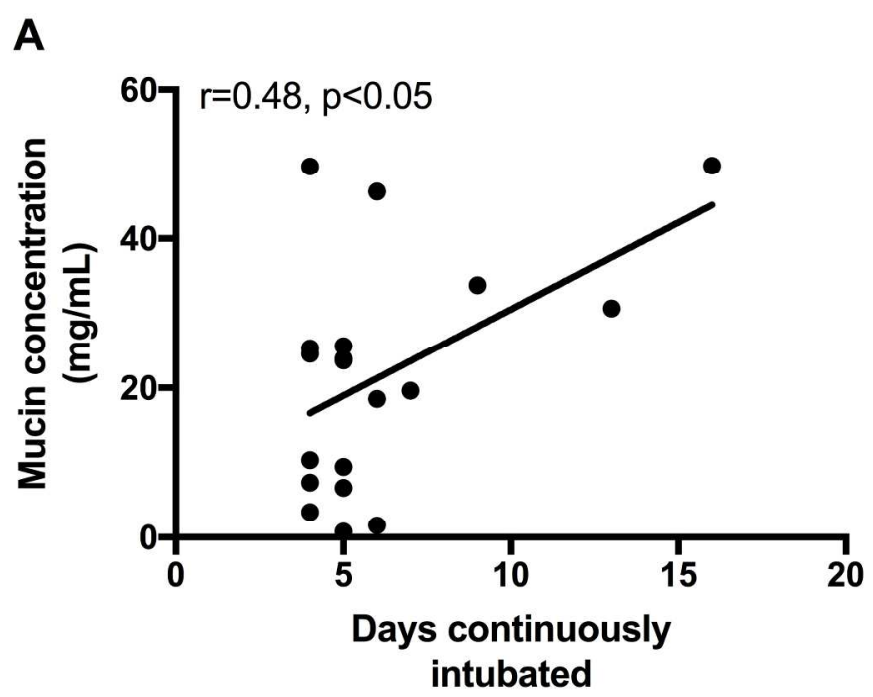

B

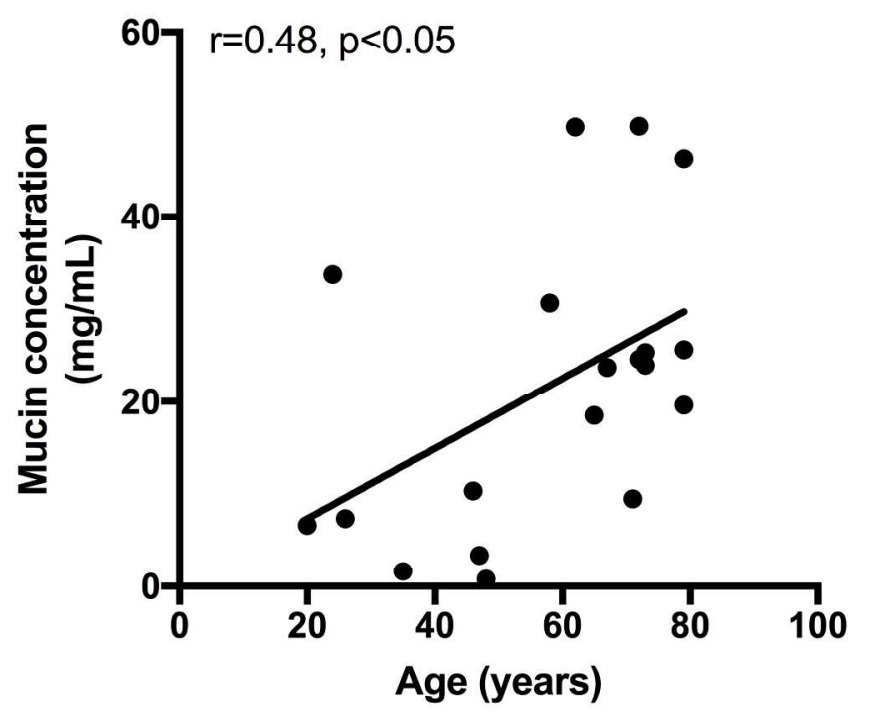

Figure E2 - Increased total mucin concentration in subglottic aspirates is associated with length of intubation and mechanical ventilation, and age. Total mucin concentrations (MUC5B and MUC5AC) in ICU aspirates were correlated with clinical parameters of length of continuous intubation and mechanical ventilation at the time of sampling (A) and the patient's age (B). Data were analyzed by linear regression and Spearman's

rank correlation test. 
A
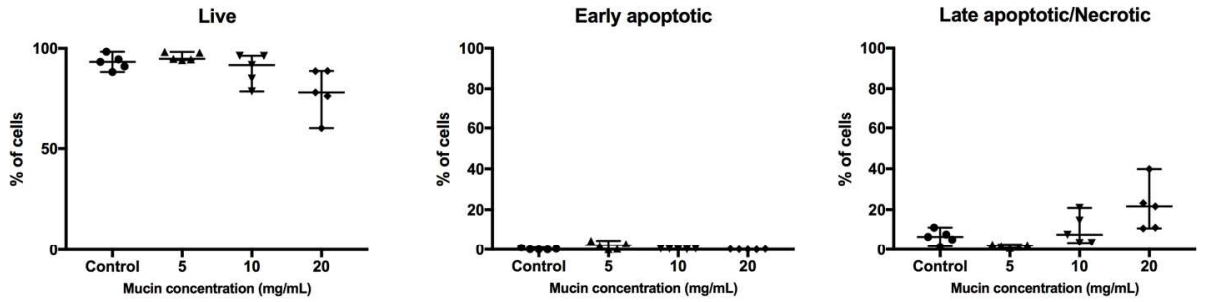

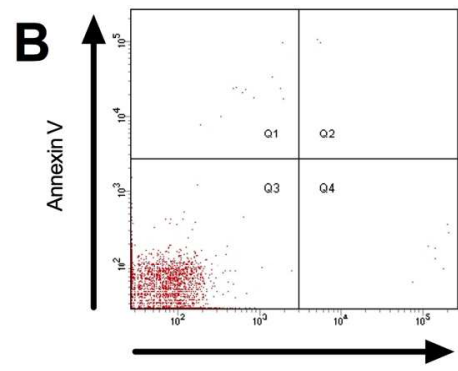

Propidium lodide

C

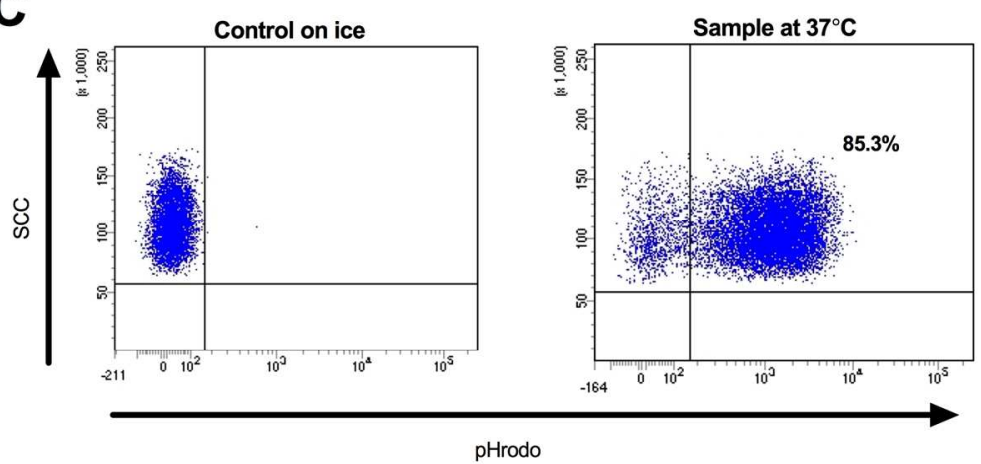

Figure E3 - Whole blood-derived neutrophils from healthy volunteers were incubated at $37^{\circ} \mathrm{C}$ in purified mucin (from ICU patients) for 1 hour prior to flow cytometric analysis of viability using Annexin V (Ann V) and propidium iodide (PI). (A) Data are expressed as median and 95\% CI. Kruskal-Wallis test and Dunn's post hoc test were used to compare the differences against the control without mucin. No significant differences were observed. (B) Representative flow cytometry plot showing viable cells (Ann $V$ negative, PI negative), early apoptotic cells (Ann V positive, PI negative), and the mixed population of late apoptosis and necrotic cells (PI positive). 

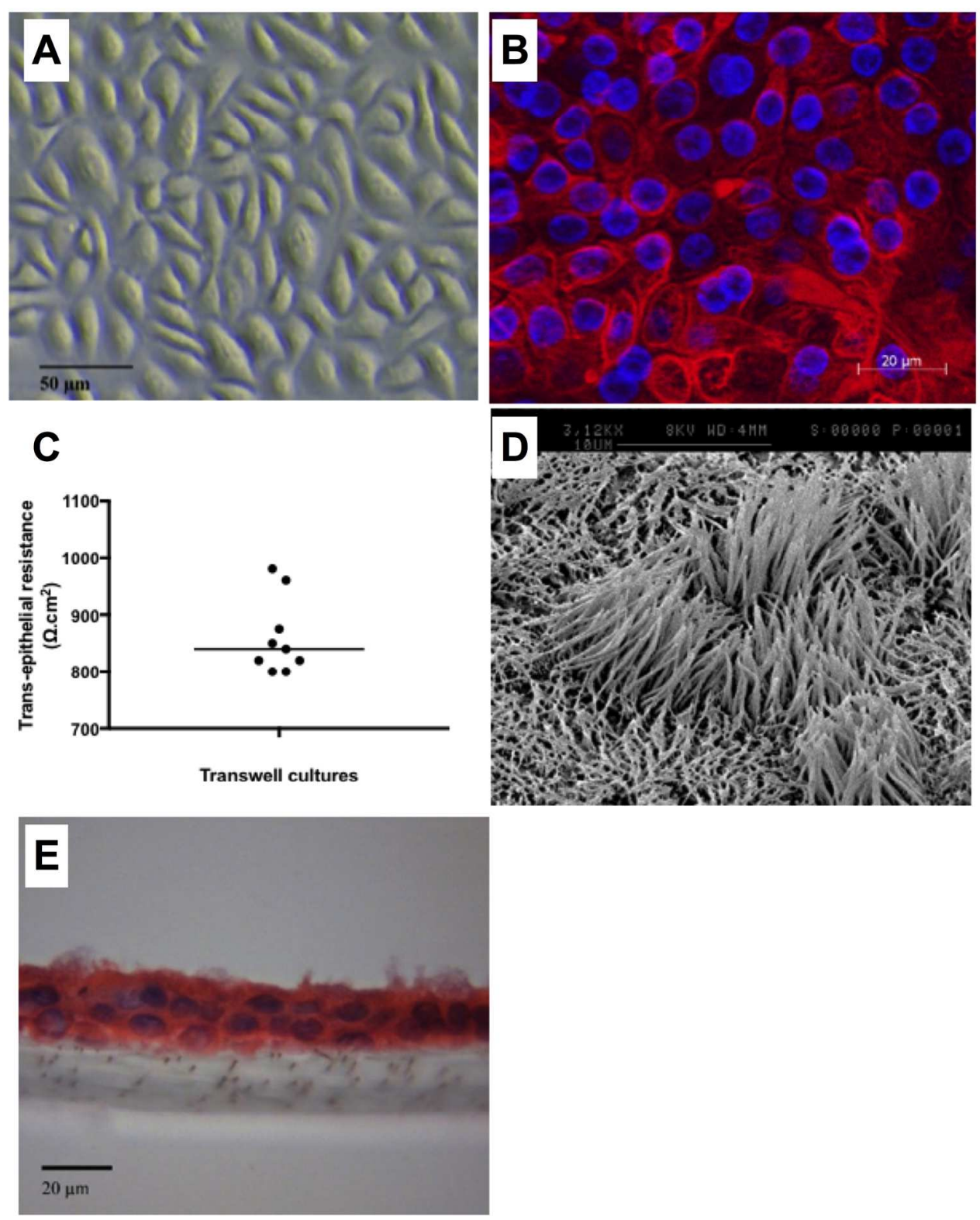

Figure E5 - (A) Submerged culture of human PSECs, with a typical cobblestone appearance on light microscopy. (B) Same sample after passage and air-liquid interface (ALI) culture. Epithelial phenotype was confirmed by expression of pan-cytokeratin (red fluorescence) and nuclei counterstained with DAPI (blue).

(C) Trans-epithelial electrical resistance measurements across epithelial cells at ALI. Horizontal line represents median value. Images are representative of 9 separate experiments. (D) Scanning electron micrograph of epithelial cells at ALI demonstrating apical cilia. (E) Brightfield micrograph image of a crosssection of cells at ALI culture (paraffin-embedded), demonstrating highly differentiated pseudostratified respiratory epithelium (including basal, ciliated, and goblet cells) supported on a transwell membrane. 
Day 8

$\mathrm{R}_{\mathrm{TE}}=1,616 \Omega \cdot \mathrm{cm}^{2}$

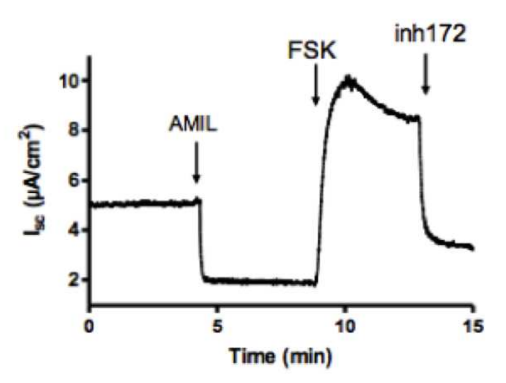

Day 28
Day 15

$$
\mathbf{R}_{\mathrm{TE}}=1,322 \Omega \cdot \mathrm{cm}^{2}
$$

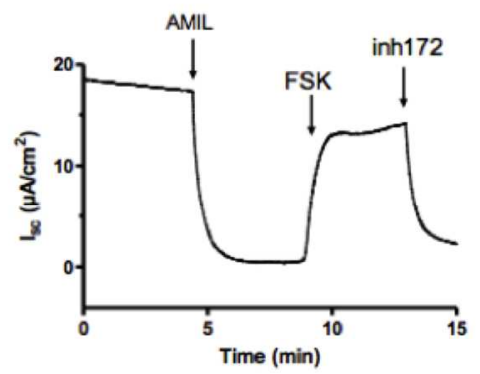

$\mathrm{R}_{\mathrm{TE}}=802 \Omega \cdot \mathrm{cm}^{2}$

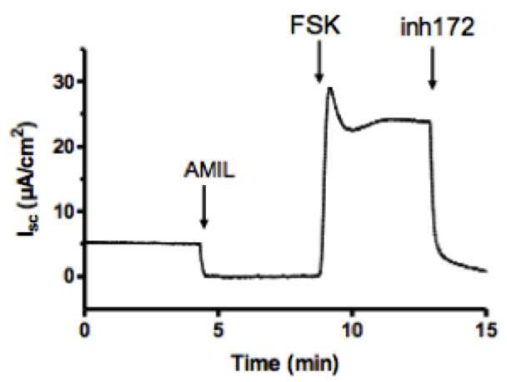

Figure E6 - Ussing chamber studies demonstrate the electrophysiological properties of PSECS at ALI over time. Human PSECs grown on Snapwells $\left(37^{\circ} \mathrm{C} 5 \% \mathrm{CO} 2\right)$ were assessed in an Ussing chamber. Short-circuit current (Isc) values reflect anion ( $\mathrm{Cl}-$ ) secretion and/or cation absorption ( $\mathrm{Na}+)$. Exposure of the epithelium to $10 \mu \mathrm{M}$ amiloride (AMIL) blocked the apical epithelial sodium channels (ENaC) in the polarized epithelial cells. $10 \mu \mathrm{M}$ forskolin (FSK) was then added to activate cAMP cascades and caused a significant elevation in whole epithelial current. $20 \mu \mathrm{M}$ inh172, a specific cystic fibrosis transmembrane conductance regulator (CFTR) inhibitor, reversed this elevated Isc current, which demonstrated that the majority of the forskolin response was attributable to CFTR. Resistance was monitored by applying $5 \mathrm{mV}$ voltage pulses at 30 second intervals and monitoring the change in Isc (not shown). The resistance was multiplied by the surface area of the transwell, to give an electrical resistance value in $\Omega . \mathrm{cm} 2$. Resistance values shown are initial measurements. Data from one representative experiment. 

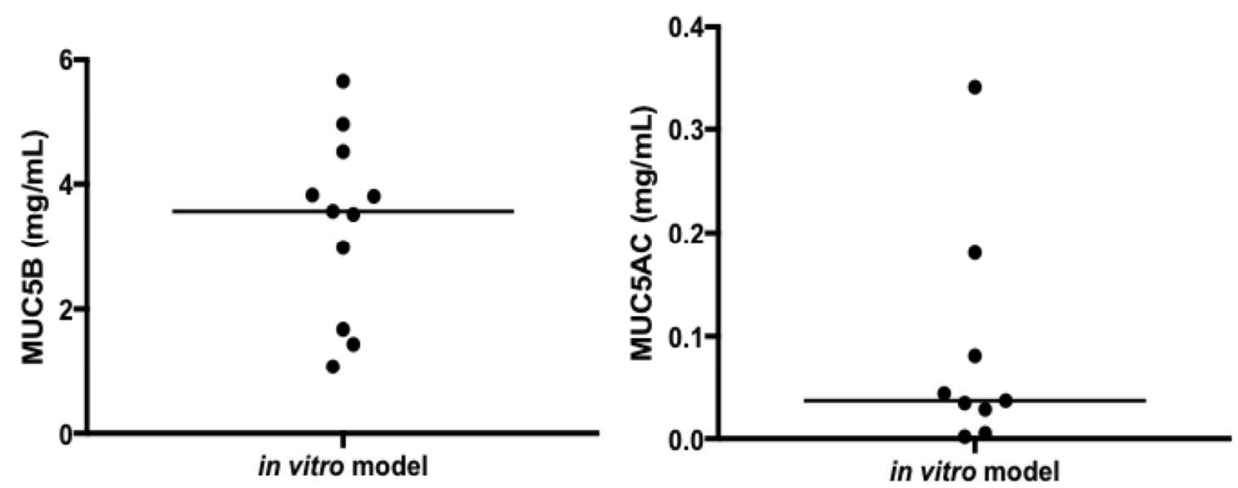

Figure E7 - Apical secretions collected from PSECs at ALI, demonstrating airway mucins MUC5B and MUC5AC. Mucin concentrations were quantified from apical aspirates and measured by ELISA. Horizontal bars depict median values, $n=11$ MUC5B, $n=9$ MUC5AC.

$160 \times 62 \mathrm{~mm}(300 \times 300 \mathrm{DPI})$ 